\title{
Absence of RIPK3 predicts necroptosis resistance in malignant melanoma
}

\author{
P Geserick', J Wang ${ }^{1,2}$, R Schilling ${ }^{1}$, S Horn ${ }^{1}$, PA Harris ${ }^{3}$, J Bertin $^{3}$, PJ Gough ${ }^{3}$, M Feoktistova ${ }^{1,2}$ and M Leverkus ${ }^{\star, 1,2}$
}

Acquired or intrinsic resistance to apoptotic and necroptotic stimuli is considered a major hindrance of therapeutic success in malignant melanoma. Inhibitor of apoptosis proteins (IAPs) are important regulators of apoptotic and necroptotic cell death mediated by numerous cell death signalling platforms. In this report we investigated the impact of IAPs for cell death regulation in malignant melanoma. Suppression of IAPs strongly sensitized a panel of melanoma cells to death ligand-induced cell death, which, surprisingly, was largely mediated by apoptosis, as it was completely rescued by addition of caspase inhibitors. Interestingly, the absence of necroptosis signalling correlated with a lack of receptor-interacting protein kinase-3 (RIPK3) mRNA and protein expression in all cell lines, whereas primary melanocytes and cultured nevus cells strongly expressed RIPK3. Reconstitution of RIPK3, but not a RIPK3-kinase dead mutant in a set of melanoma cell lines overcame CD95L/IAP antagonistinduced necroptosis resistance independent of autocrine tumour necrosis factor secretion. Using specific inhibitors, functional studies revealed that RIPK3-mediated mixed-lineage kinase domain-like protein (MLKL) phosphorylation and necroptosis induction critically required receptor-interacting protein kinase-1 signalling. Furthermore, the inhibitor of mutant BRAF Dabrafenib, but not Vemurafenib, inhibited necroptosis in melanoma cells whenever RIPK3 is present. Our data suggest that loss of RIPK3 in melanoma and selective inhibition of the RIPK3/MLKL axis by BRAF inhibitor Dabrafenib, but not Vemurafenib, is critical to protect from necroptosis. Strategies that allow RIPK3 expression may allow unmasking the necroptotic signalling machinery in melanoma and points to reactivation of this pathway as a treatment option for metastatic melanoma.

Cell Death and Disease (2015) 6, e1884; doi:10.1038/cddis.2015.240; published online 10 September 2015

Over the past few years, necroptosis has been established as an alternative programmed form of cell death, contrasting caspase-dependent apoptosis. It is now evident that an ordered activation of the receptor-interacting protein kinases-1 and -3 (RIPK1 and RIPK3), and their downstream substrates is mandatory for the execution of necroptosis. ${ }^{1-3}$ Under caspase-limited conditions, the necroptotic cell signalling machinery is regulated by RIPK1, with the impact of scaffolding function as compared with kinase function still unclear. ${ }^{1,4-6}$ RIPK1 interacts with and either autophosphorylates or transphosphorylates RIPK3 (for review, see Cho et al., ${ }^{1}$ Zhang et al., ${ }^{2}$ He et al., ${ }^{3}$ and Vanden Berghe et al. ${ }^{7}$ ). When RIPK1 is active, RIPK3 phosphorylation and activation occurs within the assembled Necrosome (for review, see Remijsen et al. ${ }^{8}$ ) or Ripoptosome ${ }^{4,9,10}$ RIPK3 then phosphorylates the pseudo kinase mixed-lineage kinase domain-like protein (MLKL). ${ }^{11}$ MLKL in its active form allows its oligomerization, membrane accumulation, and complex formation within cellular membranes of the mitochondria ${ }^{12}$ and cell membranes, ${ }^{13}$ and finally results in necroptosis. ${ }^{14}$
The RIPK1/RIPK3/MLKL signalling network acts as a sensor for genotoxic stress ${ }^{9}$ and also has a key role in necroptosis regulation in keratinocyte skin cancer (SCC). ${ }^{4}$ In these epithelial cancers, cellular inhibitors of apoptosis proteins (clAPs) block both apoptotic and necroptotic cell death. ${ }^{4,5}$ Both apoptosis and necroptosis can be increasingly initiated by intrinsic or extrinsic stimuli when IAPs are suppressed by IAP antagonist. Extrinsic apoptosis mediated by activation of death receptors (DRs) such as cluster of differentiation 95 (CD95), TRAILR1/R2 or tumour necrosis factor receptor-1 (TNFR1) through ligation of respective death ligands (DLs) such as CD95L, TNF-related apoptosisinducing ligand (TRAIL), and TNF initiates apoptosis either by direct activation of the caspase cascade (caspase-8/ caspase-3) or via the intrinsic cell death signalling machinery regulated by pro-apoptotic members of the Bcl-2 family followed by caspase-3 activation. ${ }^{15}$ Inhibition of caspase-8 within the death-inducing signalling complex or complex II, or within the Ripoptosome can trigger CD95L-mediated, ${ }^{5}$ TRAIL-mediated ${ }^{16}$ or TNF-induced necroptosis. ${ }^{8,17} \mathrm{~A}$ role for

\footnotetext{
${ }^{1}$ Section of Molecular Dermatology, Department of Dermatology, Venerology and Allergology, Medical Faculty Mannheim, University Heidelberg, Mannheim, Germany; ${ }^{2}$ Department for Dermatology and Allergology, University Hospital Aachen, RWTH Aachen, Aachen, Germany and ${ }^{3}$ Pattern Recognition Receptor Discovery Performance Unit, Immuno-Inflammation Therapeutic Area, GlaxoSmithKline, Collegeville, PA 19426, USA

*Corresponding author: Dr M Leverkus, Department for Dermatology and Allergology, University Hospital Aachen, RWTH Aachen, Pauwelsstrasse 30, 52074 Aachen Germany. Tel: +49 0621383 1643; Fax: +49 0621383 4085; E-mail: mleverkus@ukaachen.de

Abbreviations: CD95, cluster of differentiation 95; CIAP1/2, cellular inhibitor of apoptosis protein-1/2; DL, death ligand; DMSO, dimethyl sulfoxide; DR, death receptor; ERK, extracellular signal-regulated kinase; FACS, fluorescence-activated cell sorting; IAP, inhibitor of apoptosis protein; KD, kinase dead; MEK, mitogen-activated protein/ extracellular signal-regulated kinase kinase; MLKL, mixed-lineage kinase domain-like protein; NSA, necrosulfonamide; Nec-1/Necro-1, necrostatin-1; PI, propidium iodide; RIPK1, receptor-interacting protein kinase-1; RIPK3, receptor-interacting protein kinase-3; TRAIL, TNF-related apoptosis-inducing ligand; TNF, tumour necrosis factor; TNFR2, tumour necrosis factor receptor-2; XIAP, X-linked IAP

Received 27.4.2015; revised 07.7.2015; accepted 13.7.2015; Edited by G Raschellà
} 
apoptosis resistance, cancer maintenance, and progression is widely assumed (for review, see Obexer et al. ${ }^{18}$ ), but the pathophysiological inhibitory or propagating function of necroptosis has not formally been demonstrated in cancer.

Metastatic melanoma has an overall poor prognosis but novel therapeutics have revolutionized clinical practice for different subsets of patients. The use of inhibitors of the V600E- or V600K-mutated proto-oncogene serine/threonine protein kinase B-RAF (e.g., Dabrafenib or Vemurafenib) results in suppression of Ras/Raf/mitogen-activated protein kinase pathways and translate into unfortunately transient clinical responses (for review, see Spagnolo et al. ${ }^{19}$ ). The high recrudescence of metastatic melanoma following the treatment with BRAF inhibitors will potentially require combination therapies that activate additional tumour-inhibitory pathways. Combinations such as BRAF inhibitors with mitogen-activated protein/extracellular signal-regulated kinase kinase (MEK) inhibitors have already yielded impressive results ${ }^{20}$ and other combination therapies may further improve clinical outcome. ${ }^{21}$ As BRAF inhibitors target the cell death pathway at best in an indirect manner, we reasoned that necroptosis induction could represent a novel option to improve melanoma therapy. Our investigations demonstrate for the first time that loss of RIPK3 during melanoma development is critical for necroptosis protection. Reactivation of the RIPK1/RIPK3/MLKL signalling machinery by RIPK3 reconstitution allows IAP antagonist/ DL-mediated necroptosis in the presence of Vemurafenib, but not Dabrafenib. Here, Dabrafenib blocks necroptosis by interference with RIPK3-mediated MLKL phosphorylation. Therefore, strategies that increase RIPK3 expression in combination with Vemurafenib, but not Dabrafenib, likely represent an attractive strategy to overcome cell death resistance in melanoma.

\section{Results}

IAP antagonists sensitize malignant melanoma cells to apoptosis, but not to necroptosis. To investigate the role of IAPs in malignant melanoma, we initially analysed and compared protein expression of different IAPs in cultured primary melanocytes, nevus cells, and malignant melanoma representing different tumour stages and compared them with HaCaT keratinocytes (Figure 1a). clAP1 and X-linked IAP (XIAP) are expressed in most of the melanoma cell lines examined with lower clAP1 levels in PREYER, MeWo, IGR, and MM-LH. Low XIAP expression was found in primary melanocytes, MeWo and IGR cells, whereas XIAP is absent in $\mathrm{HaCaT}$ keratinocytes as previously described. ${ }^{22}$ In contrast, clAP2 expression was only detected at low levels in A375 and EP cells, but undetectable in primary melanocytes, nevus cells, and all other melanoma cell lines. Of interest, we detected an additional band reactive with clAP1 antibody (Ab) in primary melanocytes, nevus cells, as well as in SK-Mel and MM-AH melanoma cells, suggesting that clAP1 may undergo posttranslational modifications in these cells (Figure 1a). When clAP1/clAP2 expression or XIAP function is suppressed by IAP antagonist compound $A^{23}$ (Supplementary Figure 1A), sensitivity to CD95L-mediated cell death is increased. This sensitization was largely independent from the concentrations of IAP antagonist used (Supplementary Figure $1 \mathrm{~B}$ and $\mathrm{C}$ ). In addition, low concentrations of IAP antagonists were sufficient for a subtotal decrease of clAP1 in IGR and also of clAP2 in A375 cells. This indicates that XIAP is rather more critical as clAPs for cell death resistance in melanoma cells. In further investigations, we analysed the quality and quantity of IAP antagonist/ CD95L-mediated cell death in the presence or absence of a pancaspase inhibitor (zVAD-fmk; Figures 1b and c) in four melanoma cell lines. Under those conditions, melanoma cells were strongly sensitized to DL-mediated caspase-dependent (zVAD-fmk) (Figure 1b, black columns and Figure 1c) but RIPK1-independent (Nec-1), as shown by Annexin-V/propidium iodide $(\mathrm{PI})$ double staining (Figure 1c), apoptosis when compared with cells treated with CD95L alone (Figure 1b, grey columns). Our results demonstrate the indispensable role of IAPs for inhibition of CD95L-mediated apoptotic cell death and suggest that melanoma cells are intrinsically resistant to necroptotic cell death.

RIPK3 expression is lost during melanoma development. We next reasoned that the lack of necroptosis in melanoma could be a result of a melanoma cell-intrinsic inhibition of proteins relevant for necroptosis induction. We thus examined RIPK1, RIPK3, and MLKL at mRNA and protein levels (Figures $2 \mathrm{a}$ and $\mathrm{b}$ ). When compared with $\mathrm{HaCaT}$ keratinocytes that express high levels of RIPK $3,{ }^{4}$ primary melanocytes and nevus cells demonstrated high RIPK3 expression. In marked contrast, expression of RIPK3 is extremely low (A375, MC, IGR, and MM-LH) or fully absent in melanoma cells. MLKL and RIPK1 protein was present in most melanoma cell lines, nevus cells, and primary melanocytes. In addition, PREYER, MeWo, and MM-AN cells showed low or absent expression of MLKL (Figure 2a). To investigate whether the absence of RIPK3 expression was a result of a lack of transcription of RIPK3, we next investigated mRNA expression of RIPK3. When compared with $\mathrm{HaCaT}$ keratinocytes, primary melanocytes (Mel \#20 but not Mel \#19) and both cultured nevus cells highly expressed RIPK3 mRNA. In marked contrast, RIPK3 mRNA expression was absent or below detection level in all melanoma cell lines studied (Figure 2b). Taken together, these observations raised the possibility that the lack of RIPK3 mRNA and protein expression explains the absence of necroptosis in melanoma cells.

RIPK3 allows for IAP antagonist/CD95L-induced necroptosis in malignant melanoma. To functionally investigate the role of RIPK3 in apoptotic and necroptotic cell death in melanoma, we next reconstituted RIPK3 in a number of melanoma cell lines (Figure 3a). Successful RIPK3 overexpression, but not its kinase-inactive mutant D160N (RIPK3-kinase dead (KD) ${ }^{1}$ in A375, EP or IGR cells resulted in spontaneous MLKL phosphorylation (Figure 3a), indicating that reconstitution of functional RIPK3 is sufficient to phosphorylate a known downstream target. We next analysed the respective RIPK3-expressing melanomas for DR-induced, caspase-dependent or -independent cell death (Figures $3 \mathrm{~b}$ and $\mathrm{c}$ and Supplementary Figures $1 \mathrm{~A}$ and $\mathrm{C}$ ). Only RIPK3 increasingly promoted CD95L-mediated cell death in A375 cells (Figure $3 b$ ) and to a lesser extent, in 
a

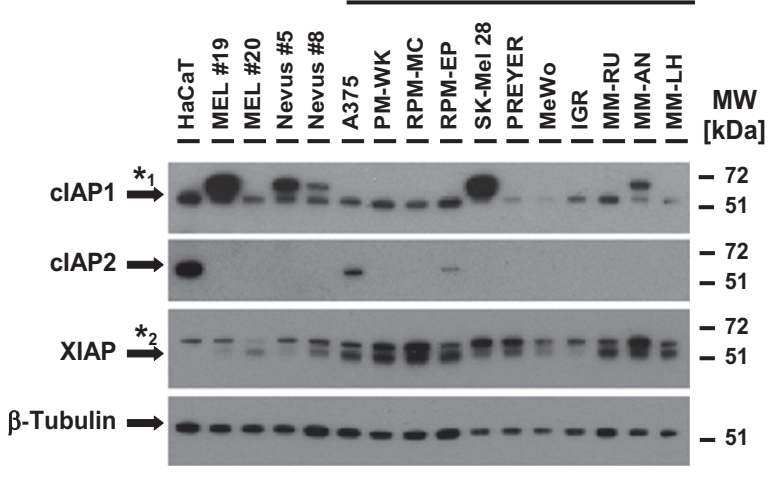

b

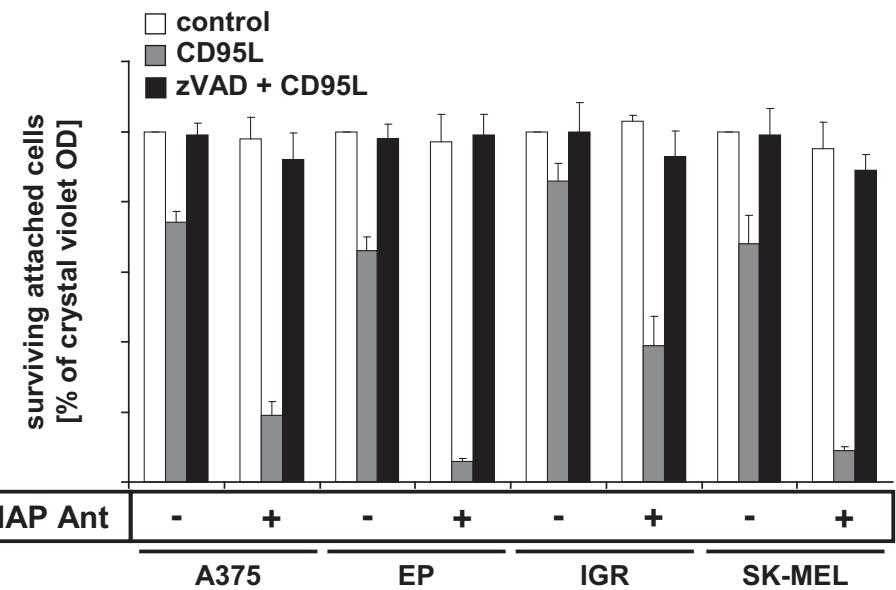

C

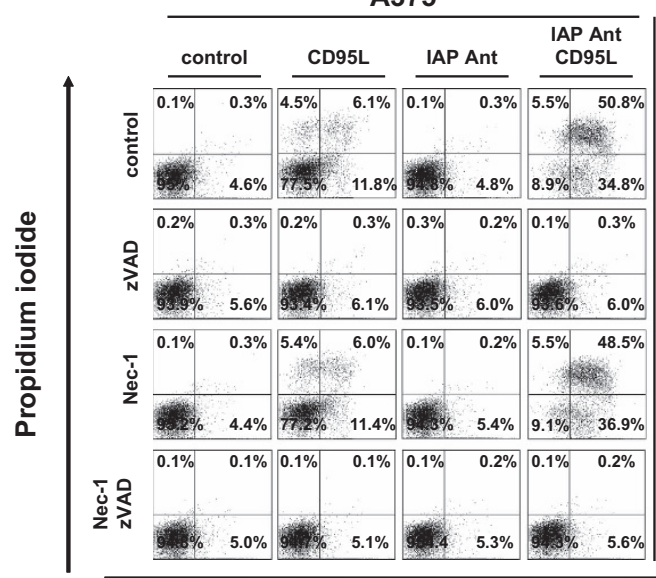

A375

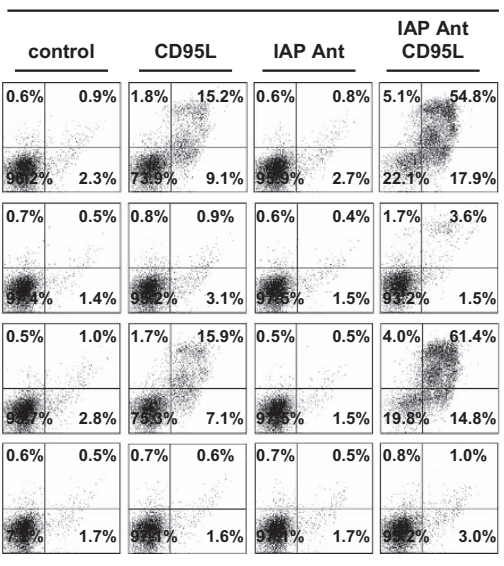

IGR

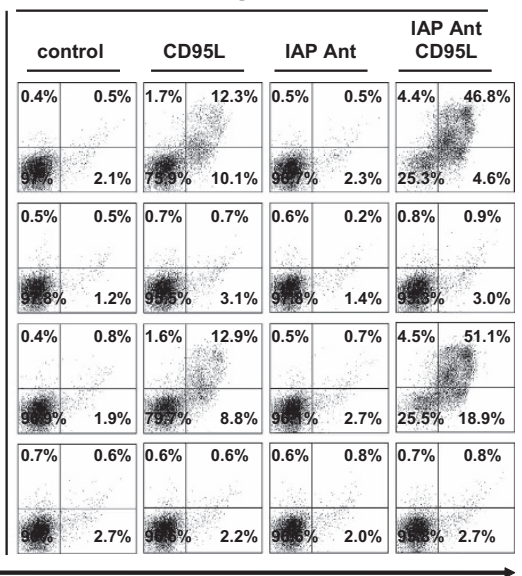

Annexin V

Figure 1 Suppression of IAPs by IAP antagonists in melanomas promotes increased sensitivity to CD95L-induced apoptotic but not necroptotic cell death. (a) Heterogeneous expression of cIAP1, cIAP2, and XIAP in HaCaT keratinocytes, primary melanocytes (Mel \#19, Mel \#20), nevus cells (Nevus \#5and \#8), and different melanoma cell lines was identified by western blot analysis. Five micrograms of total protein lysates were separated with 4-12\% NuPAGE gradient gels before detection of clAP1 (" 1 describes an unspecific band detected with cIAP1 Abs), cIAP2, XIAP ( ${ }^{2}$ describe an unspecific band recognized by the used XIAP antibody) proteins, and $\beta$-tubulin as loading control by western blot analysis. One representative experiment of a total of two experiments is shown. (b and $\mathbf{c}$ ) IAP inhibition promotes CD95L-induced apoptotic but not necroptotic cell death. (b) A375, IGR, SK-MEL and EP melanoma cells were either non-stimulated or pre-stimulated with zVAD-fmk (10 $\mu \mathrm{M})$ or IAP antagonist (100 nM) alone or in combination for $1 \mathrm{~h}$ before stimulation or costimulation with CD95L $(0.5 \mathrm{U} / \mathrm{ml})$ for $18-24 \mathrm{~h}$. Surviving attached cells were quantified with crystal violet assay as described in Materials and Methods section. Summary of multiple independently performed experiments (three to four experiments) is shown and S.E.M. was determined accordingly. (c) IAP antagonist/ CD95L-induced cell death in melanomas is caspase but not RIPK1 kinase dependent. A375, EP, and IGR melanoma cells were either pre-stimulated with DMSO and Ethanol (control), zVAD-fmk $(10 \mu \mathrm{M})$, Nec-1 $(50 \mu \mathrm{M})$, or IAP antagonist (100 nM) alone or in respective combinations for $1 \mathrm{~h}$ followed by stimulation or costimulation with CD95L (0.5 U/ml) for further $14 \mathrm{~h}$. The externalization of phosphatidylserine as well as the amount of death cells were analysed by AnnexinV/PI double staining as detailed in Materials and Methods. One representative of two independently performed experiments is shown

IGR cells (Supplementary Figure 2A), indicating that active RIPK3 participates in apoptosis regulation as recently demonstrated. $^{24,25}$ Moreover, the sensitivity to CD95Lmediated cell death was further increased whenever IAPs were inhibited (Figures $3 \mathrm{~b}$ and $\mathrm{c}$ and Supplementary Figure $2 \mathrm{~A}$ and $\mathrm{C}$ ), in line with the data in the parental cell lines (Figure 1b). However, whenever caspase activity was inhibited (zVAD-fmk), both CD95L and IAP antagonist/ CD95L treatment exclusively unmasked necroptosis in cells expressing functional RIPK3 (Figures $3 \mathrm{~b}$ and $\mathrm{c}$ and Supplementary Figure 2C). These results support the conclusion that RIPK3 protein and its kinase activity are not only involved in regulation of apoptosis but also required for necroptosis execution in melanoma. We further observed an altered cell death morphology in melanoma cells with functional RIPK3, whenever caspases are blocked (Figure 3d). In the presence or absence of clAPs, cell death exhibited apoptotic morphology on CD95L stimulation, including membrane blebbing, independent of RIPK3 expression. In contrast, another rounded cellular morphology together with a swollen cytoplasm, disintegrated nuclei (HOECHST and SYTOX Green positivity) was detected in the presence of zVAD-fmk indicative of necroptosis (Figure 3d). In summary, reconstitution of functional RIPK3 in melanoma cell lines increasingly promotes DL-induced apoptosis and unmasked DL-induced necroptosis in the 
a
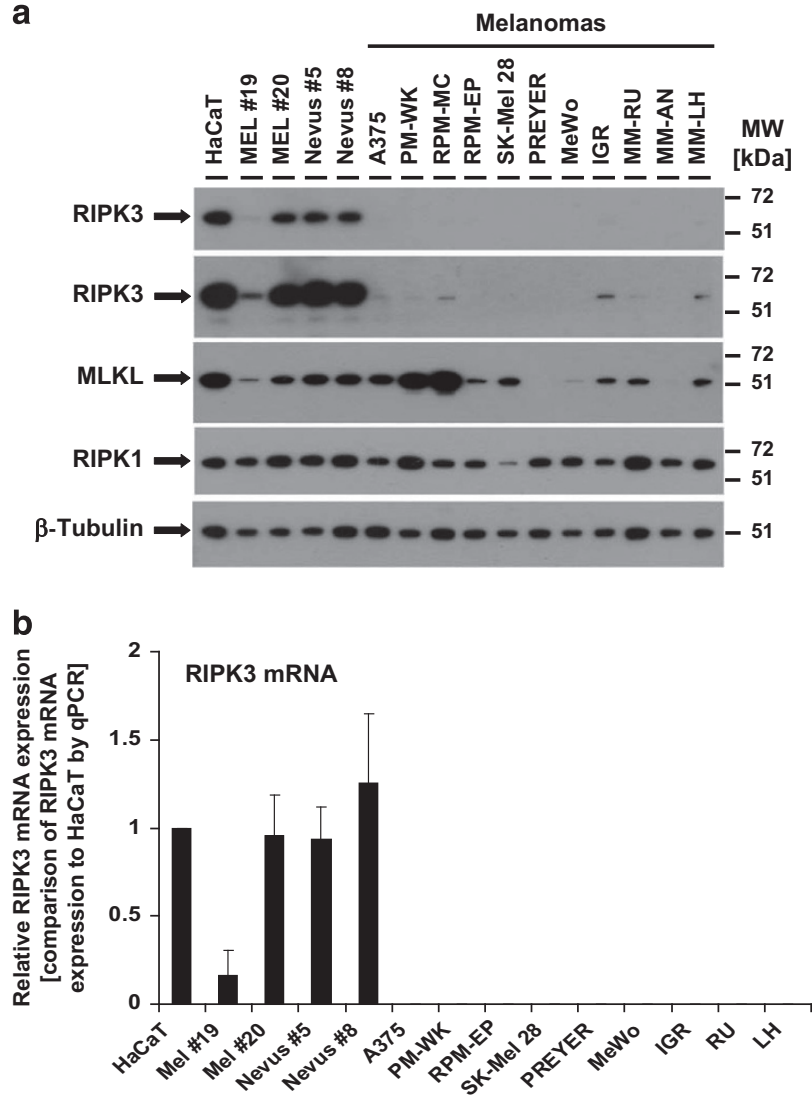

Figure 2 RIPK3 mRNA and protein expression is absent in melanoma. (a) Expression of RIPK3, MLKL, RIPK1, and $\beta$-tubulin as loading control were analysed by western blot analysis from $\mathrm{HaCaT}$ keratinocytes, primary melanocytes (Mel \#19 and Mel \#20), Nevus cells (Nevus \#5 and \#8), and different melanoma cell lines. Five micrograms of total protein lysates were separated with 4-12\% NuPAGE gradient gels before detection of respective proteins by western blot analysis. One representative experiment of a total of two experiments is shown. (b) Total mRNA from HaCaT cells, primary melanocytes (Mel \#19 and Mel \#20), Nevus cells (Nevus \#8), and six melanoma cell lines were isolates, reverse transcribed followed by analysis of RIPK3 mRNA expression, as well as housekeeping gene (actin) by quantitative PCR analysis. The mRNA expression of RIPK3 in melanocytes, nevus cells, and melanomas was compared with RIPK3 mRNA expression from HaCaT keratinocytes that serves as control. Summary of two independently performed experiments is shown. The S.E.M. is indicated by error bars

absence of caspase and IAP activity. Therefore, functional RIPK3 is necessary for apoptosis and necroptosis execution in malignant melanoma.

IAP antagonists can activate autocrine TNF production in a subset of tumour cells. ${ }^{26-29}$ We successfully inhibited TNFmediated apoptosis in previous studies ${ }^{5}$ as well as our control conditions (Supplementary Figure $3 A-D$ ) by recombinant TNFR2-Fc. However, CD95L-induced cell death in RIPK3expressing melanoma cells or their respective controls was unaltered by addition of TNFR2-Fc. This supports that neither apoptosis nor necroptosis in RIPK3-expressing A375 and IGR melanoma cells is dependent on autocrine TNF signalling.

RIPK3 activates spontaneous and clAP-protected MLKL phosphorylation. For the execution of necroptosis, RIPK3mediated phosphorylation of MLKL requires the interaction of kinase-active RIPK1 with RIPK3 (for review, see Vanden
Berghe et $a .^{7}$ ), but RIPK3 overexpression is also able to promote necroptosis independent from RIPK1 activity. ${ }^{25,30}$ To further elaborate the role of RIPK1/RIPK3 activities in necroptosis execution, we analysed cell death responses of RIPK3-expressing melanoma cells in the presence of the RIPK1 inhibitor Necrostatin-1 (Nec-1) in more detail. ${ }^{31}$ Inhibition of RIPK1 alone did not alter CD95L-induced cell death when IAPs were suppressed irrespective of the level of RIPK3 expression in melanoma cells, indicative of dual activation of necroptosis and apoptosis ${ }^{5}$ (Figures $4 a$ and b). As demonstrated for TNF-mediated necroptosis, ${ }^{30}$ RIPK3expressing A375 (Figures $4 a$ and b) or, to a lesser extent, IGR melanoma cells (Supplementary Figure 2B and C, lower result panel), but not control transduced melanoma cells, were not fully protected from IAP antagonist/CD95L treatment by ZVAD-fmk and Nec-1 (Figure 4a). The inability of $\mathrm{Nec}-1$ to fully suppress IAP antagonist/CD95L-mediated necroptosis raised the possibility of a potential activation of the necroptotic signalling machinery downstream of RIPK1, as observed in other studies. ${ }^{30,32}$ Therefore, we next studied the kinetics and extent of MLKL phosphorylation in the presence or the absence of clAPs (Figures $4 c$ and $d$ ) under conditions of necroptosis induction (zVAD/CD95L versus zVAD/IAPantagonist/CD95L) in RIPK3-reconstituted melanoma cells. MLKL phosphorylation was detected in a time-dependent manner within $90 \mathrm{~min}$, with further increase up to $6 \mathrm{~h}$ after stimulation in RIPK3-expressing, but not in RIPK3-KD or vector control melanoma cells (Figure 4c). Suppression of clAPs by IAP antagonist also resulted in an increase in MLKL phosphorylation in RIPK3-reconstituted cells (Figure 4d). These experiments suggested that MLKL phosphorylation indeed not only occurs in a strict RIPK3-dependent manner but is also a consequence of DL stimulation with further increase on clAPs depletion. Of interest, CD95L stimulation led to a marked shift of the RIPK3-specific signals to a slightly higher molecular weight, indicative of posttranslational modification. This shift may likely be explained by autophosphorylation of RIPK3 on CD95L stimulation.

CD95L-induced MLKL phosphorylation and necroptosis depends on RIPK1 and RIPK3 kinase activity. Given the intricate balance of RIPK1 and RIPK3, and their functions as scaffold molecules or kinases, respectively, we next investigated the impact of recently reported chemical inhibitors of RIPK1 and RIPK3 in more detail ${ }^{24,33}$ (Figure 5a). Spontaneous MLKL phosphorylation mediated by RIPK3 overexpression (Figure 4c) is fully suppressed by RIPK3 inhibitors (GSK'840 and GSK'872), but not inhibited by RIPK1 inhibitors (7-Cl-O-Nec-1 and GSK'481A) ${ }^{33,34}$ or Nec-1 (Figure 5a). Our findings led us to conclude that RIPK3 overexpression can promote DL-induced necroptosis independently from RIPK1 activity as previously demonstrated. ${ }^{25,30}$ In contrast, IAP antagonist/zVAD/CD95L-induced MLKL phosphorylation in RIPK3-expressing melanomas was partially suppressed by Nec-1 and other RIPK1 inhibitors but fully suppressed by any of the used RIPK3 inhibitors. RIPK3 inhibition and MLKL phosphorylation correlated with full inhibition of necroptosis (Figure 5b). Furthermore, the lack of complete necroptosis protection by Nec-1 (Figures $4 \mathrm{a}$ and b) also correlated with at best partial suppression of MLKL 


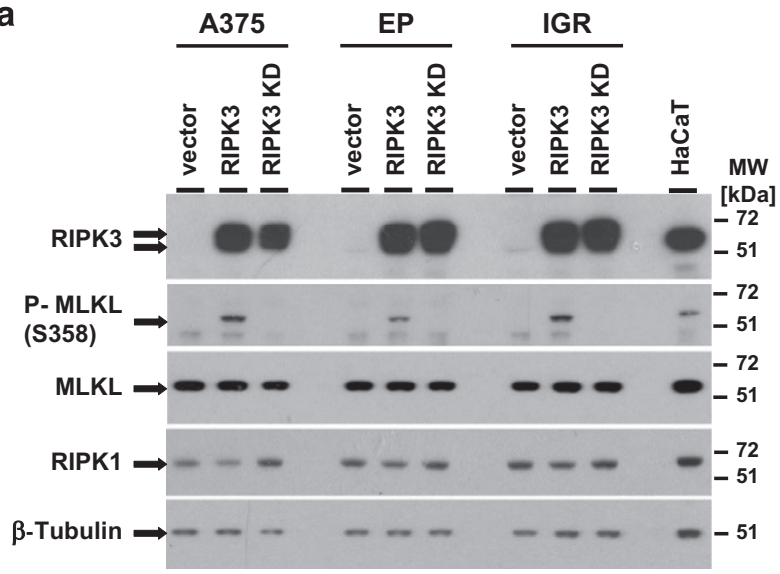

\section{b $\begin{aligned} 120 & \square \text { Vector } \\ \square & \text { RIPK3 } \\ \square & \text { RIPK3 KD }\end{aligned}$}

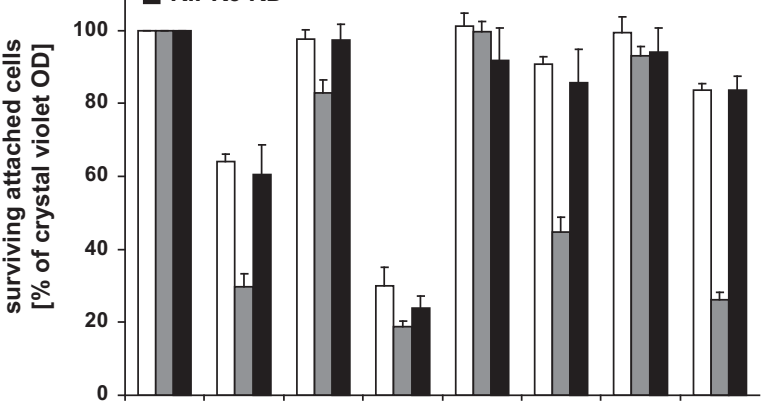

\begin{tabular}{|c|cccccccc|}
\hline CD95L & - & + & - & + & - & + & - & + \\
\hline IAP Ant & - & - & + & + & - & - & + & + \\
\hline zVAD & - & - & - & - & + & + & + & + \\
\hline
\end{tabular}

C

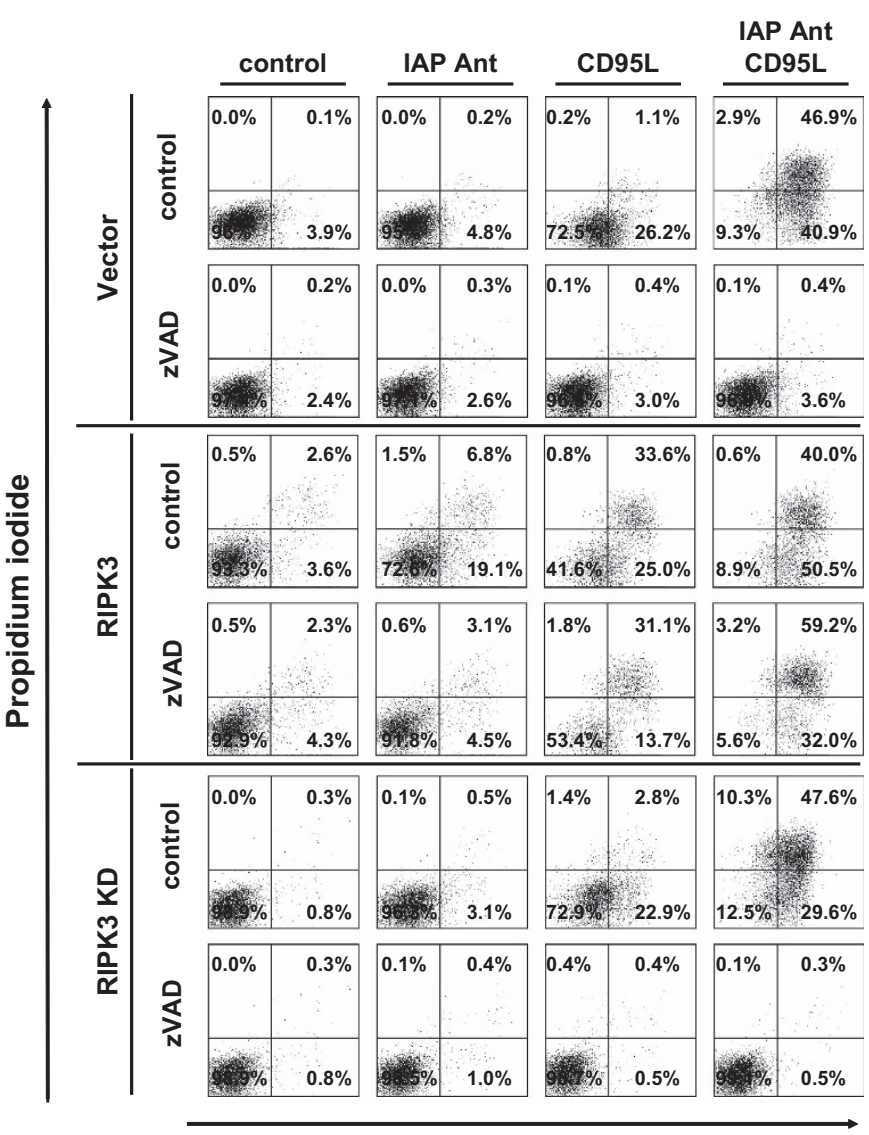

Annexin V

d

RIP3

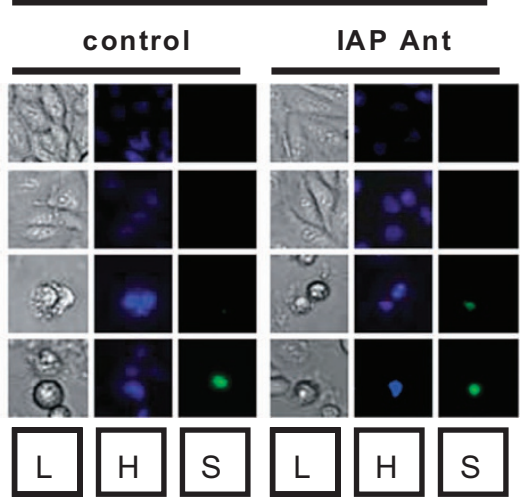

IAP Ant

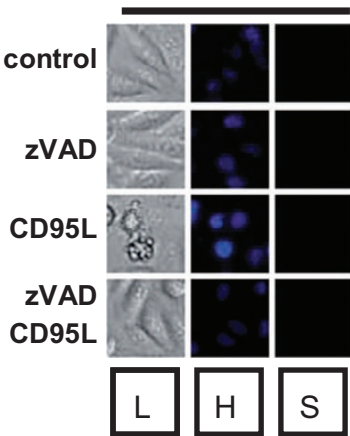

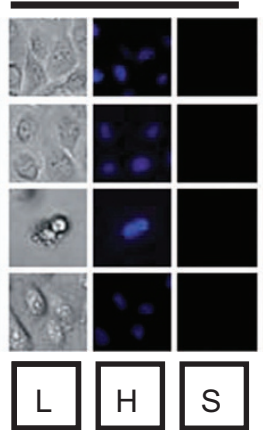

Figure 3 Reconstitution of RIPK3, but not of RIPK3-KD, promotes spontaneous MLKL phosphorylation and necroptotic cell death. (a) Overexpression of RIPK3 and RIPK3-KD (D160N) in melanomas. Retroviruses expressing human RIPK3 or RIPK3-KD, or vector controls were used for transduction of A375, RPM-EP, and IGR melanoma cells. Transduced cells were selected and analysed for RIPK3 overexpression, as well as for MLKL, p-MLKL, and $\beta$-tubulin as loading control. Five micrograms of total protein lysates were separated with 4-12\% NuPAGE gradient gels before detection of respective proteins by western blot analysis. One representative experiment of a total of three independent performed experiments is shown. (b-d) RIPK3 but not RIPK3-KD promotes caspase-independent cell death. (b) A375 cells with expression of control (vector), RIPK3, and RIPK3-KD were either non-stimulated or pre-stimulated with ZVAD-fmk $(10 \mu \mathrm{M})$ or IAP antagonist $(100 \mathrm{nM})$ alone or in combination for $1 \mathrm{~h}$ before stimulation or costimulation with CD95L (0.5 U/ml) for 18-24 h. Surviving attached cells were quantified with crystal violet assay as described in Materials and Methods. Summary of multiple independent performed experiments (four experiments) including the S.E.M. of all experiments is depicted. (c) For phosphatidylserine (PS) externalization and cell death quantification, AnnexinV/PI double stainings was performed. A375 cells with expression of control (vector), RIPK3, and RIPK3-KD were pre-stimulated with DMSO/Ethanol (control), ZVAD-fmk (10 $\mu \mathrm{M}$ ), or IAP antagonist (100 nM) alone or in respective combination for $1 \mathrm{~h}$ before stimulation or costimulation with CD95L $(0.5 \mathrm{U} / \mathrm{ml})$ for $14 \mathrm{~h}$. Externalization of PS and cell death were analysed after Annexin V/PI double staining by FACS analysis as described in Materials and Methods section. One of two independent experiments is shown representatively. (d) A375 cells with expression of the respective constructs were stimulated as described in c followed by qualitative characterization of cell death by fluorescent microscopy after Hoechst/Sytox green double staining as detailed in the Materials and Methods section. One of two independent experiments is shown (L, through Light-microscopy; H, Hoechst staining; S, Sytox green staining) 


$$
\text { a }
$$

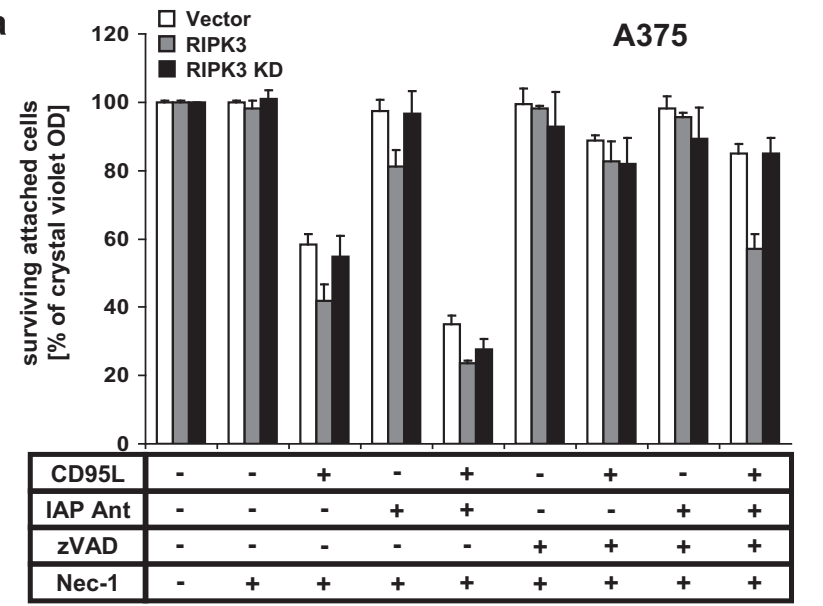

b

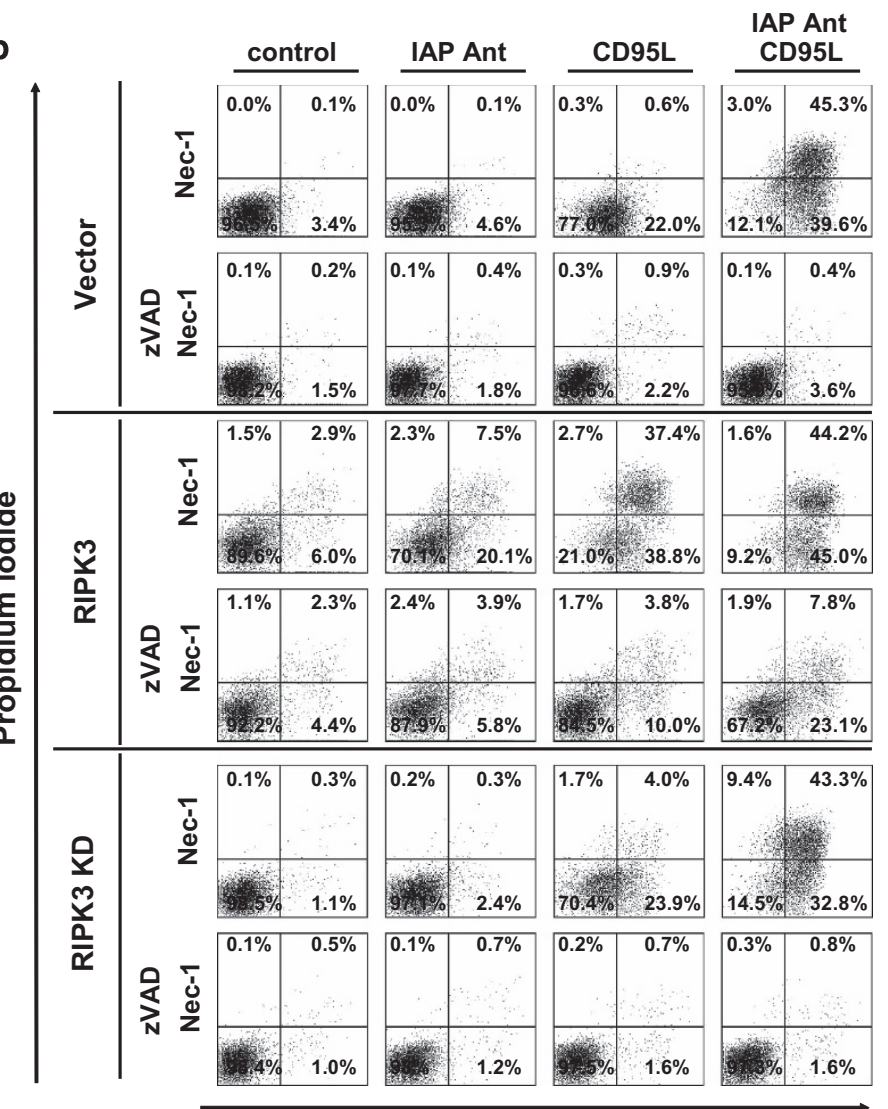

C

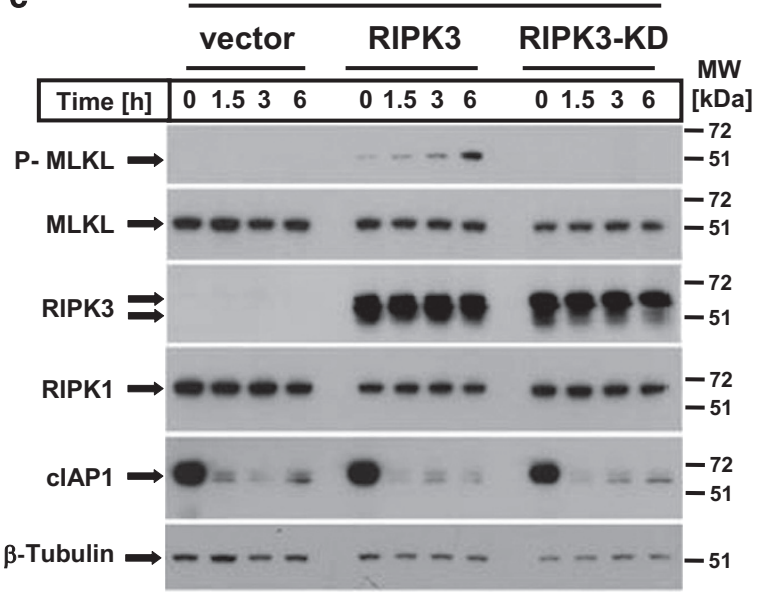

d

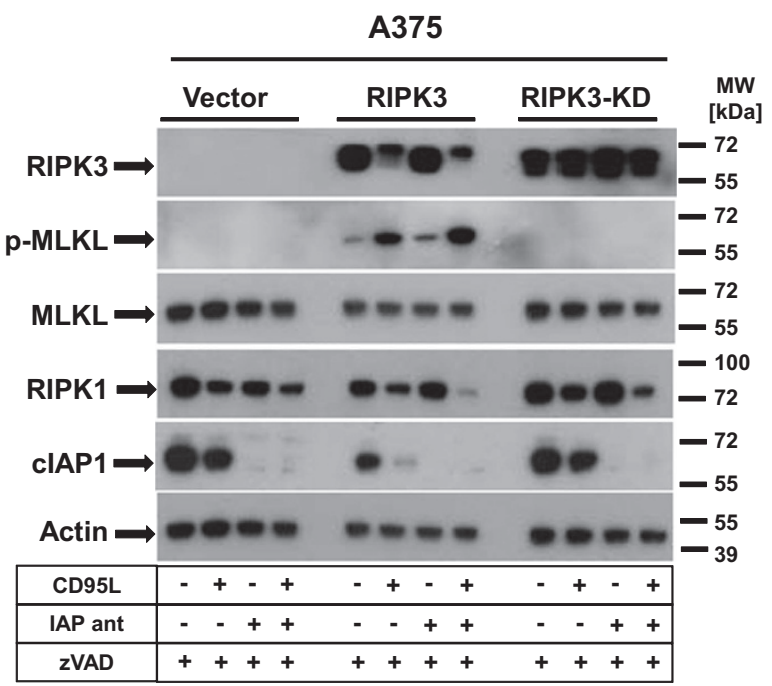

\section{Annexin V}

Figure 4 CD95L/IAP antagonist-induced necroptosis in RIPK3-re-expressing A375 cells is partially RIPK1 kinase independent and promotes MLKL phosphorylation. (a-c) CD95L/AP antagonist-mediated necroptosis but not CD95L-induced apoptosis in RIPK3-expressing A375 cells is partially RIPK1. (a and b) Control, RIPK3-, and RIPK3KD-expressing A375 cells were either pre-stimulated with Nec-1 $(50 \mu \mathrm{M})$, zVAD-fmk $(10 \mu \mathrm{M})$, or IAP antagonist (100 nM) alone or in respective combination for $1 \mathrm{~h}$ before stimulation or costimulation with CD95L $(0.5 \mathrm{U} / \mathrm{ml})$ for $18-24 \mathrm{~h}(\mathbf{a})$, for $14 \mathrm{~h}(\mathbf{b})$, followed by analysis with respective methods. (a) Crystal violet staining was performed as previously described. Summary of multiple independently performed experiments (four experiments) including the S.E.M. of all experiments is depicted. (b) Externalization of phosphatidylserine (PS) and cell death was analysed after Annexin V/PI double staining by FACS analysis as described in Materials and Methods section. One of two independent experiments is shown representatively. For analysis of MLKL phosphorylation, vector control, RIPK3-, and RIPK3-KD-expressing A375 cells were stimulated with IAP antagonist ( $1 \mathrm{~h}$ prestimulation with $100 \mathrm{nM}$ ) followed by CD95L $(0.5 \mathrm{U} / \mathrm{ml})$ stimulation for the indicated time $(\mathbf{c})$. The respective cell lines were either separately pre-stimulated or co-stimulated with IAP antagonist ( $1 \mathrm{~h}$ pre-stimulation with $100 \mathrm{nM}$ ) and zVAD-fmk (1 h pre-stimulation with $10 \mu \mathrm{M})$, followed by CD95L treatment $(0.5 \mathrm{U} / \mathrm{ml})$ for $6 \mathrm{~h}(\mathrm{~d})$. Phosphorylation of MLKL as well as expression of MLKL, RIPK3, RIPK1, CIAP1, actin, and $\beta$-tubulin was analysed by western blot analysis as previously described. One of three (c) and one of two (d) representative and independently performed experiments is shown 


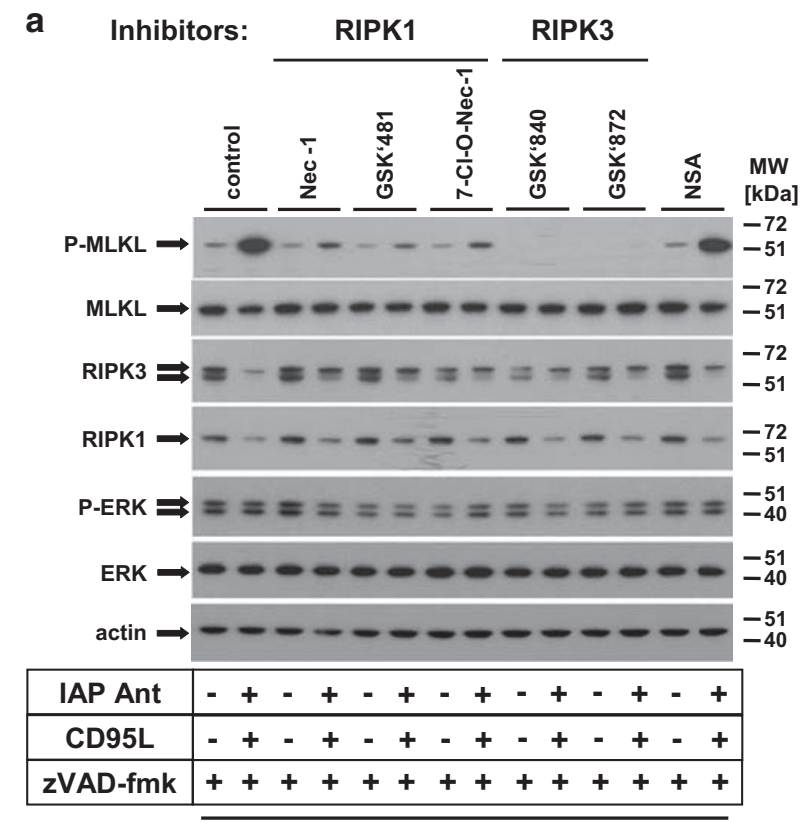

A375 RIPK3

b

b $\square$ control

$\square$ IAP Ant+CD95L

$120] \begin{aligned} & \text { ZVAD } \\ & \text { ZVAD+IAP Ant+CD95L }\end{aligned}$

A375

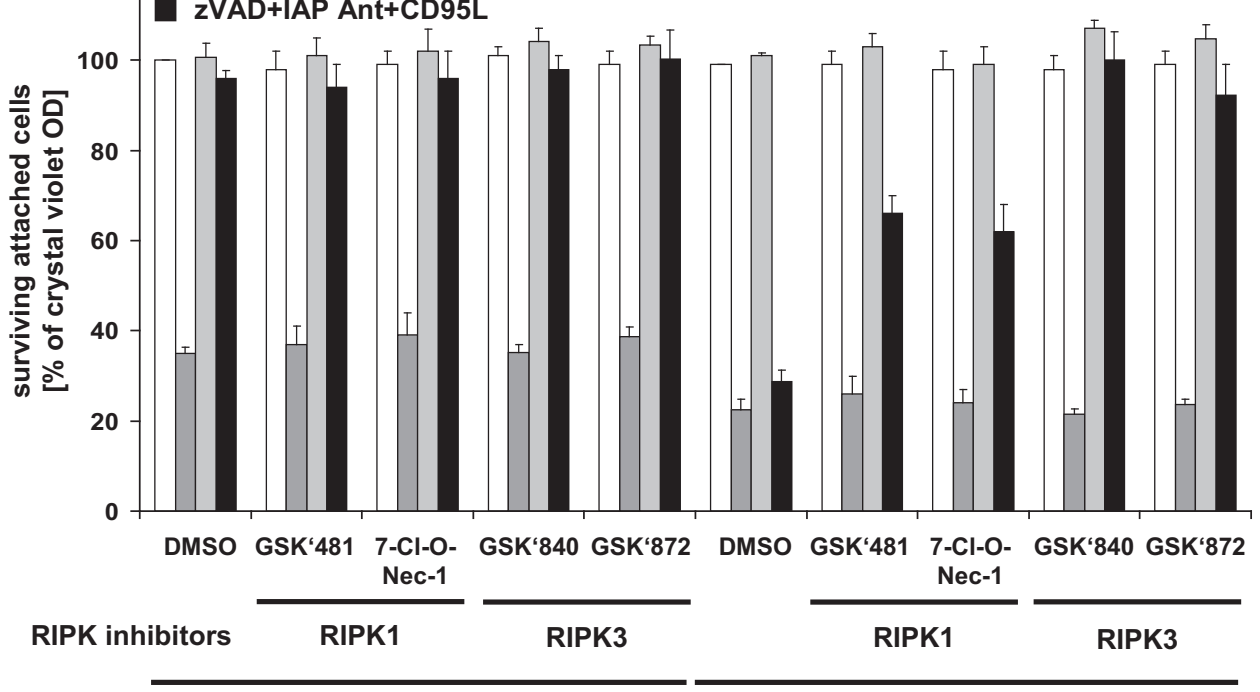

vector

RIPK3

Figure 5 CD95L/zVAD/IAP antagonist-mediated necroptosis induction and MLKL phosphorylation depends on RIPK1 and RIPK3. (a) MLKL phosphorylation in RIPK3 expressing cells depends on RIPK1 and RIPK3. RIPK3-overexpressing A375 melanomas were either pre-treated with IAP antagonist (100 nM), zVAD-fmk (10 $\mu \mathrm{M})$, Nec-1 $(50 \mu \mathrm{M})$, NSA $(10 \mu \mathrm{M})$, RIPK3 kinase inhibitor (GSK'840 and GSK'872) or RIPK1 inhibitors (7-Cl-O-Nec-1 and GSK'481; $10 \mu \mathrm{M}$ each) alone or in respective indicated combinations for $1 \mathrm{~h}$ followed by CD95L (0.5 U/ml) costimulation for $6 \mathrm{~h}$. Phosphorylation of MLKL or ERK as well as expression of MLKL, RIPK3, RIPK1, ERK, and actin was analysed by western blot analysis as previously described. One of three representative independently performed experiments is shown. (b) RIPK3 inhibitors fully protect RIPK3 reconstituted melanomas against CD95L/AP antagonist-mediated necroptosis. Vector control and RIPK3-expressing cells were either pretreated with IAP antagonist (100 nM), zVAD-fmk (10 $\mu \mathrm{M})$, RIPK3 kinase inhibitor (GSK'840 and GSK'872), or RIPK1 inhibitors (7-Cl-O-Nec-1 and GSK'481) alone or in respective combinations followed by CD95L $(0.5 \mathrm{U} / \mathrm{ml})$ costimulation for $18-24 \mathrm{~h}$ followed by analysis with crystal violet assay as described previously. Summary of multiple independently performed experiments (three experiments) is shown including the S.E.M. of the whole set of experiments

phosphorylation (Figure 5a). Our experiments show that both RIPK3-mediated spontaneous and DL/IAP antagonistinduced MLKL phosphorylation and subsequent necroptosis induction require RIPK3 activity. In contrast, RIPK1 activity is critical for DL-induced, but not for RIPK3-initiated spontaneous MLKL phosphorylation. However, as our experiments show, the previously published inhibitor of MLKL-mediated necroptosis (NSA, necrosulfonamide) ${ }^{11}$ was unable to suppress 
MLKL phosphorylation (Figure 5a, NSA treatment), and necroptosis inhibition (data not shown) in our cellular models. In summary, our data show that spontaneous MLKL phosphorylation is RIPK3 dependent but is not associated with spontaneous necroptosis induction, indicating that Phospho-MLKL under those conditions either accumulates in an inactive form that is not able to translocate into cellular membranes. Alternatively, there may exist other proteins that bind to and block MLKL translocation and necroptosis, as suggested. ${ }^{14}$ As an additional alternate explanation, additional triggers may be required for MLKL phosphorylation, membrane translocation and finally necroptosis execution.

Dabrafenib, but not Vemurafenib, interferes with MLKL phosphorylation and necroptosis signalling in RIPK3-expressing melanoma. BRAF mutations that result in constitutive cell proliferation are present in roughly $50 \%$ of malignant melanoma. ${ }^{35}$ The BRAF inhibitors Vemurafenib or Dabrafenib suppress proliferation of BRAF-mutated melanoma cells, ${ }^{36}$ but surprisingly Dabrafenib effectively suppresses RIPK3 activity as an off-target effect. ${ }^{37}$ Thus, it is intriguing to speculate that the effectiveness of a therapy with BRAF inhibitors could be hampered (or altered) by interference with necroptosis/RIPK3 signalling. We therefore explored conditions of necroptosis induction in the presence of Dabrafenib or Vemurafenib in our model systems. In line with the recent report, Dabrafenib but not Vemurafenib blocked necroptosis (Figures $6 \mathrm{a}$ and $\mathrm{b}$; black bars) and MLKL phosphorylation (Figures $6 \mathrm{c}$ and d), but also protected from DL/IAP antagonist-mediated apoptosis (Figures 6a and b; grey bars) in RIPK3-reconstituted A375 or IGR melanoma cells. Interestingly, both inhibitors strongly repressed extracellular signal-regulated kinase (ERK) phosphorylation in IGR, but not in A375 cells (Figures 6c and d). Our observations thus indicate that in contrast to Vemurafenib, Dabrafenib is a potent inhibitor of MLKL phosphorylation and consequently protects from necroptosis. This was a more general phenomenon for DR signalling, as Dabrafenib also inhibited TRAIL (Supplementary Figures 4A and B) and TNF-mediated necroptosis (Supplementary Figures $4 C$ and $D)$, in line with a recent report in primary and transformed keratinocytes. $^{38}$ Taken together, the absence of RIPK3 or blockade of RIPK3 activity by the respective inhibitors or the BRAF inhibitor Dabrafenib, but not Vemurafenib, are able to block DL-mediated necroptotic and, to some extent, apoptotic cell death in melanoma.

\section{Discussion}

Targeted therapeutics that suppress melanoma growth such as BRAF inhibitors Vemurafenib or Dabrafenib, or the direct MEK inhibitors Cobimetinib or Tranetinib, ${ }^{36}$ have revolutionized metastatic melanoma therapy and have at last improved patient survival. As these therapeutics lose their effectiveness within months, most likely by activation of alternative MEK signalling, ${ }^{39}$ innovative treatments may require additional direct triggering of alternative tumour-specific cell death pathways. ${ }^{40}$ Inhibition of IAPS is one promising strategy to activate cell death and is currently under clinical investigation in various cancer types (for review, see Wan et al. ${ }^{41}$ ).
In keratinocyte skin cancer, we described the inhibitory function of clAPs for apoptosis and necroptosis. ${ }^{4,5}$ In the current report we investigated the impact of RIPK1 and RIPK3 kinase for apoptosis and necroptosis in malignant melanoma.

Our analysis of a large number of cultured melanoma cells identified largely uniform expression of XIAP and cIAP1, but not of clAP2. Thus, IAP antagonists may represent promising compounds to sensitize melanoma cells to cell death triggering, possibly in combination with other targeted therapies or chemotherapeutics (for review, see Obexer et $a l^{18}$ ). We detected a substantially increased sensitivity to CD95L-mediated apoptosis but not necroptosis when IAP activity was suppressed. Thus, XIAP and/or clAPs protect melanoma cells from DL-induced apoptosis (CD95L) as also found in breast ${ }^{42}$ or pancreatic cancer. ${ }^{43}$ XIAP/cIAPs suppression by macrocyclic XIAP antagonists in melanoma and breast cancer support cell death induction and tumour growth inhibition in vivo, ${ }^{44}$ indicative of the indispensable protective role of IAPs in many cancer entities. In our studies, melanomas surprisingly lacked the execution of RIPK1dependent necroptosis, usually uncovered when caspase function is blocked. A pure apoptotic cell death response has been documented in different tissues of genetic mouse models whenever single genes coding for essential components of the necroptotic cell death machinery are absent, most prominently MLKL or RIPK3. ${ }^{24,45-48}$

When we examined the cause for loss of necroptosis, we uncovered the vast absence of RIPK3 protein expression in melanomas when compared with melanocytes and nevus cells. The lack of protein expression was mediated by a lack of RIPK3 mRNA (Figure 2) as previously described in lung cancer $^{49}$ and in colon cancer ${ }^{50}$ or in subtypes of metastatic melanoma. ${ }^{51}$ A more general lack of RIPK3 mRNA can be a result of limited promoter activation controlled by epigenetic DNA modification such as DNA methylation, histone deacetylation ${ }^{52}$ or regulated by tumour-initiating signals such as chronic hypoxia. ${ }^{50}$ Thus, our observation and the correlation between necroptosis protection and low RIPK3 expression in melanoma raises the possibility that progression of malignant melanoma may require silencing of RIPK3-dependent necroptosis, or alternatively other RIPK3-dependent signalling pathways, as suggested. ${ }^{53}$ These different hypotheses await experimental clarification in the future.

Previous investigations demonstrated the indispensable role of RIPK3 in cell death regulation during embryonic development, ${ }^{54-56}$ stimulation with different ligands of the TNF superfamily, ${ }^{5,57}$ TLR3 agonists, ${ }^{4,58}$ during etoposidemediated stress responses ${ }^{9}$ and on interferon signalling or during virus infections. ${ }^{7,59,60}$ In our study, reconstitution of RIPK3 not only increased apoptosis as recently reported ${ }^{8,24}$ but also allowed reactivation of necroptosis in melanoma whenever IAPs are inhibited. Consistent with our observation that human RIPK3-KD mutant D160N is unable to transmit necroptosis, reconstitution of murine kinase-inactive RIPK3-KD mutants such as $\mathrm{D} 161 \mathrm{~N}^{45}$ or $\mathrm{D} 143 \mathrm{~N}$, or $\mathrm{K} 51 \mathrm{~A}^{25}$ also fail to induce necroptosis, indicating that the RIPK3 catalytic activity is indispensable for necroptotic cell death. ${ }^{24}$ In contrast to the observed apoptosis induction in murine cells that expressed the RIPK3 kinase-inactive mutant $\mathrm{D} 161 \mathrm{~N},{ }^{24,45}$ reconstitution 

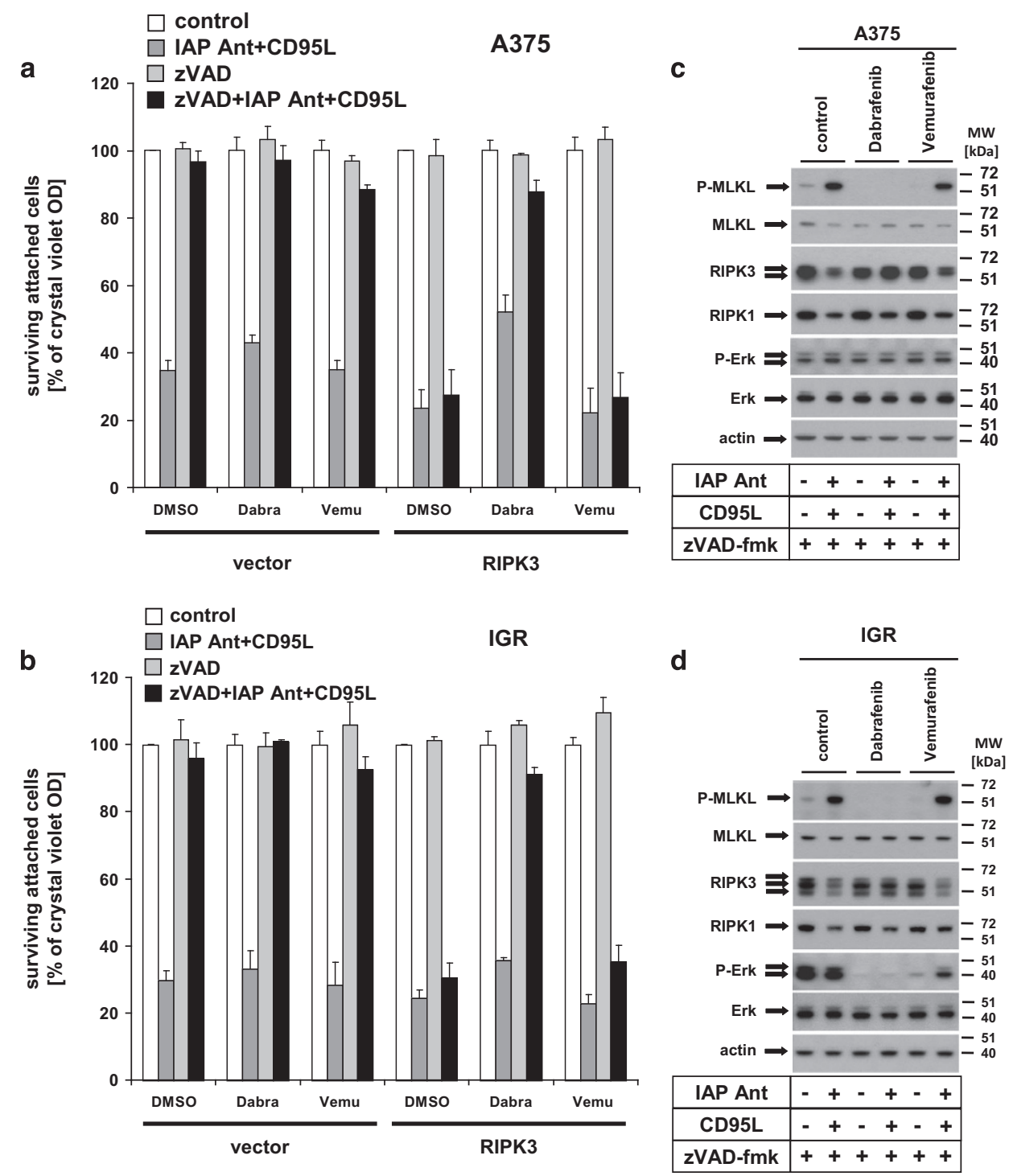

Figure 6 Dabrafenib, but not Vemurafenib, suppresses DL/AP antagonist-mediated necroptosis by inhibition of MLKL phosphorylation. (a and b) Dabrafenib blocks necroptosis in RIPK3-reconstituted melanomas. Vector control and RIPK3-expressing A375 (a) or IGR (b) melanomas were either pretreated for $2 \mathrm{~h}$ with IAP antagonist (100 nM), zVAD-fmk (10 $\mu$ M), Dabrafenib $(10 \mu \mathrm{M})$, or Vemurafenib (A375 with $30 \mu \mathrm{M}$ and IGR with $10 \mu \mathrm{M}$ ) alone or in respective combinations followed by CD95L (0.5 U/ml) costimulation for 18-24 h and analysis with crystal violet assay as described previously. Summary of three independently performed experiments is shown. The S.E.M. of the whole set of experiments is depicted. (c and $\mathbf{d}$ ) Dabrafenib but not Vemurafenib inhibits MLKL phosphorylation in RIPK3-reconstituted A375 (c) and IGR (d) melanomas. RIPK3-expressing A375 (c) or IGR (d) melanomas were either pretreated for $2 \mathrm{~h}$ with IAP antagonist $(100 \mathrm{nM})$, zVAD-fmk $(10 \mu \mathrm{M})$, Dabrafenib $(10 \mu \mathrm{M})$, or Vemurafenib (A375 with $30 \mu \mathrm{M}$ and IGR with $10 \mu \mathrm{M})$ alone or in respective combinations followed by CD95L $(0.5 \mathrm{U} / \mathrm{ml})$ costimulation for $6 \mathrm{~h}$. Phosphorylation of MLKL or ERK as well as expression of MLKL, RIPK3, RIPK1, ERK, and actin was analysed by western blot analysis as previously described. One of three independently performed experiments is shown as representation of the results

of human RIPK3-D160N did not interfere with spontaneous apoptosis or led to altered sensitivity to DL or IAP antagonist, indicating that the RIPK3 catalytic activity is dispensable for apoptosis. Thus, our data extend the previous notion that RIPK3 may either be a critical downstream target or a necessary part of intracellular signalling complexes such as the Necrosome or Ripoptosome. If RIPK3 acts as a kinase or may also modulate the stoichiometry of protein complexes by a presumed scaffold function is an intriguing question that needs to be addressed in the future. ${ }^{24,61}$

Interestingly, RIPK3-expressing melanoma cells, but not RIPK3-KD cells, show spontaneous and increased MLKL phosphorylation (Figure 4c), a strong indication that kinase activity of RIPK3 is the missing link for DL-mediated necroptosis in melanomas. Both spontaneous and IAP antagonist/DL-mediated MLKL phosphorylation following necroptosis induction is blocked in the presence of specific RIPK3 inhibitors. ${ }^{24}$ These data demonstrate (a) the functionality of RIPK3 for activation of its downstream target within the necroptotic signalling machinery and (b) the requirement of the kinase function for this phosphorylation event in melanoma cells. In our previous studies, ${ }^{5}$ we found that RIPK1 was critical for necroptosis execution in SCC cells. In contrast, other cell types with high RIPK3 expression failed to be protected from cell death by interference with RIPK1 activity. ${ }^{8,25}$ When RIPK1 is inhibited by Nec-1, 7-Cl-O-Nec-1 
or GSK' $481,{ }^{62}$ our data also show a partial RIPK1independent execution of necroptosis. These results are supported by other recent reports that highlight the intricate interplay between RIPK1 and RIPK3, and its dependency from the stoichiometry of the different critical proteins. ${ }^{24,25,30}$ Taken together, the cellular context, RIPK1 and RIPK3 expression level, and known (or unknown) downstream molecules such as MLKL intensely have an impact on the cell biological response to identical stimuli. Possibly, other currently unknown signalling pathways can be activated only by RIPK3, which also involves other interacting proteins that triggers RIPK3 phosphorylation. Alternatively, RIPK3 may also assemble in homomultimers and is activated by autophosphorylation. How this influences the tumour response (e.g., activation of immune cells to dying melanoma cells) in a tumour-bearing patient remains to be elucidated in the future.

Reactivation of the RIPK1/RIPK3/MLKL signalling platform by RIPK3 reconstitution can overcome necroptosis resistance in melanoma and therefore could be used as potential deathinducing targeted therapy against melanoma. Our data presented in the current study indicate that a combination therapy of Dabrafenib or Vemurafenib together with reagents that allow RIPK3 reconstitution could be such a strategy that was tested in vitro in melanoma (Figure 6). Consistent with another recent study, ${ }^{37}$ Dabrafenib also interfered with RIPK3 activity in our study (Figure 6 and Supplementary Figure 3) and was able to block necroptosis and, to some extent, apoptosis. Based on the observation that RIPK3 also increasingly promotes apoptosis (Figures $3 \mathrm{~b}$ and $\mathrm{c}$ and Cook et $a .^{25}$ ), the described off-target effect of Dabrafenib ${ }^{37}$ for inhibition of RIPK3 activity could be responsible not only for inhibition of necroptosis but also for RIPK3-dependent apoptosis. It is also possible that other currently unknown molecules of the apoptotic signalling machinery are influenced by the off-target activity of Dabrafenib. In contrast, the alternative BRAF inhibitor Vemurafenib was unable to suppress MLKL phosphorylation and necroptosis, indicating that suppression of BRAF/MEK-mediated proliferation and RIPK3-mediated necroptosis are not interconnected. Dabrafenib-mediated necroptosis suppression strongly correlated with its inhibitory effect on MLKL phosphorylation. Although the exact molecular mechanisms how BRAF inhibition and necroptosis protection cross-talk are fully unknown, the surprising discordant response of two different BRAF inhibitors demonstrated in this study merits further attention in the future. For therapeutic intervention, the reactivation of the RIPK1/RIPK3/MLKL necroptotic signalling axis together with simultaneous inhibition of BRAF-mediated proliferation (e.g., Vemurafenib) without effecting RIPK3 activity could be an attractive strategy.

\footnotetext{
Material and Methods

Materials. The following Abs were used for western blot analysis: XIAP (H62120) (Transduction Laboratories, San Diego, CA, USA), rat Abs to CIAP1 (Silke et al. ${ }^{63}$ ) and CIAP2, ${ }^{22}$ anti- $\beta$-tubulin (clone 2.1) and anti-actin antibodies (Sigma, St Louis, MO, USA), RIPK3 polyclonal antibody (IMGENEX, San Diego, CA, USA), RIPK1 (Transduction Laboratories), anti-MLKL (phospho-S358) antibody (Abcam, Cambridge, UK), and anti-ERK-2 and anti-phospho-ERK from (Santa Cruz, Dallas, TX, USA). MLKL antibodies recognizing both mouse and human MLKL ${ }^{46}$ were kindly provided by James Murphy (WEHI, Melbourne, Parkville, Australia). Horseradish peroxidase (HRP)-conjugated goat anti-rabbit, goat anti-rat lgG, and goat
}

anti-mouse lgG Abs, and HRP-conjugated goat anti-mouse IgG1, IgG2a, and IgG2b were obtained from Southern Biotechnology Associates (Birmingham, AL, USA).

Cell culture. The human melanoma cell lines PM-WK, RPM-MC, RPM-EP, MM$\mathrm{RU}, \mathrm{MM}-\mathrm{AN}$, and MM-LH were kindly provided by Randy H Byers (Department of Dermatology, Boston University School of Medicine) and cultured as previously described. ${ }^{64}$ The following human melanoma cells were obtained either from ATCC (Manassas, VA, USA) or DSMZ (Deutsche Sammlung von Mikroorganismen und Zellkulturen $\mathrm{GmbH}$, Braunschweig, Germany) and cultured as described: A375 (ATCC CRL-1619), MeWo (ATCC HTB-65), SK-Mel-30 (SK-Mel; ACC 151), and IGR-37 (IGR; ACC 237). PREYER melanoma cells (generated from a subcutaneous melanoma metastasis) were kindly provided by A Schwaaf and EB Bröcker. Melanoma cells were cultured in complete DMEM medium (Gibco, Life Technologies, Darmstadt, Germany) with $4 \mathrm{mM}$ L-glutamine adjusted to contain $4.5 \mathrm{~g} / \mathrm{l}$ glucose, $10 \%$ fetal bovine serum (FCS Gold, PAA, Cölbe, Germany), 1\% sodium pyruvate, and HEPES buffer. Primary human melanocytes (Mel) and nevus cells were prepared as described ${ }^{65}$ and cultured in complete M2 melanocyte growth medium (PromoCell $\mathrm{GmbH}$, Heidelberg, Germany). HaCaT keratinocytes were kindly provided by Petra Boukamp (DKFZ, Heidelberg, Germany) and cultured as described. ${ }^{66}$

Substrates. For cell death induction and the analysis of quality and quantity of cell death, the following substrates were used in standard concentrations: ZVAD-fmk (Z-Val-Ala-Asp-fluoromethyl ketone; $10 \mu \mathrm{M}$ ) was purchased from Bachem (Heidelberg, Germany) and NSA (10 $\mu \mathrm{M})$ was provided by $L$ Sun and X Wang. ${ }^{11}$ Nec-1/Necro-1 $(50 \mu \mathrm{M})$ was from Sigma and RIPK3 inhibitors (GSK'840 or GSK'872; $10 \mu \mathrm{M}$ ) and RIPK1 inhibitors (GSK'481 or 7-Cl-O-Nec-1/Necro-1) were from Glaxo Smith Kline Corp. (GSK, New York, NY, USA). The IAP antagonist (compound $\mathrm{A} ; 100 \mathrm{nM}$ used in most studies) was generously provided by Tetralogics Corp., Philadelphia, PA, USA. For expression of Fc-CD95L, we used constructs published elsewhere. ${ }^{67}$ One unit of $\mathrm{Fc}-\mathrm{CD} 95 \mathrm{~L}$ was determined as a 1:500 dilution of the stock Fc-CD95L supernatant and $1 \mathrm{unit} / \mathrm{ml}$ of $\mathrm{Fc}-\mathrm{CD} 95 \mathrm{~L}$ supernatant was sufficient to kill $50 \%$ (LD50) of A375 melanoma cells, as described. ${ }^{68} \mathrm{PI}$ was obtained from Sigma, crystal violet was from VWR International (Radnor, PA, USA). TNFR2-Fc (Enbrel; Pfizer Inc., New York, NY, USA) was used at a concentration of $10 \mu \mathrm{g} / \mathrm{ml}$. HF-TNF was prepared as described ${ }^{68}$ and used at a concentration of $10 \mathrm{ng} / \mathrm{ml}$. Vemurafenib (PLX 4032) and Dabrafenib (GSK 2118436) were purchased from Seleckchem (Houston, TX, USA). All RIPK1/RIPK3 inhibitors used, and Vemurafenib and Dabrafenib were tested in preliminary experiments for cell toxicity. The highest non-toxic or low toxic concentration of the respective inhibitors was used in subsequent experiments.

Retroviral infection. To overexpress RIPK3 or RIPK3-KD (KD mutant, $D 160 N)$, the respective cDNAs were subcloned from pEGFP N1 vectors into pCFG5-IEGZ retroviral vector by standard cloning procedures and verified by sequencing. Sequence-confirmed vectors were used for transduction of A375, IGR, and EP melanoma cells, respectively. For virus production, the amphotrophic producer cell line $\Phi \mathrm{NX}$ was transfected with $10 \mu \mathrm{g}$ of the retroviral vectors by calcium phosphate precipitation. Cell culture supernatants containing viral particles were generated by incubation of producer cells with A375 medium DMEM containing 10\% FCS, sodium pyruvate, and HEPES buffer) overnight. Following filtration (45 $\mu \mathrm{M}$ filter, Schleicher \& Schuell, Dassel, Germany), culture supernatant was added to the respective melanoma cells seeded in six-well plates $24 \mathrm{~h}$ earlier in the presence of $1 \mu \mathrm{g} / \mathrm{ml}$ polybrene. After centrifugation for $2 \mathrm{~h}$ at $30^{\circ} \mathrm{C}$, viral particle containing supernatants were replaced by fresh medium. After 14 days of zeocine selection of bulk infected A375, IGR, and EP cell cultures, fluorescence-activated cell sorting (FACS) analysis for green fluorescence protein expression (always $>95 \%$, data not shown) and western blot analysis were performed on polyclonal cells to confirm ectopic expression of the respective molecules. The empty retroviral vectors served as controls. Aliquots of cells were used for the experiments between passages 2-6 after initial characterization for all subsequent studies. HaCaT cells expressing IKK2-KD and vector control were established to control for effectivity of TNF-R2-Fc for TNF-mediated apoptosis as previously described. ${ }^{22}$

Western blot analysis. Cell lysates were prepared as described ${ }^{69}$ and $5 \mu \mathrm{g}$ of total cellular proteins were separated by SDS-PAGE on $4-12 \%$ gradient gels (Invitrogen, Karlsruhe, Germany) followed by transfer to nitrocellulose or PVDF membranes. Blocking of membranes and individual incubation with primary and appropriate secondary Abs were performed as recommended by the 
companies respectively. Bands were visualized with ECL detection kits (Amersham, Freiburg, Germany).

Immunofluorescence microscopy. For detection of nuclear morphology and integrity of the cell membrane, $5 \times 10^{4}$ A375 cells expressing vector control, RIPK3, and RIPK3-KD were seeded per well in a 12-well plate. Following $24 \mathrm{~h}$ of incubation for adherence, cells were stimulated as indicated in the figure legend for $14 \mathrm{~h}$. Subsequently, cells were incubated with Hoechst $33342(5 \mu \mathrm{g} / \mathrm{ml}$; Polysciences Europe, Eppelheim, Germany) and SYTOX Green (5pM; Invitrogen, Molecular Probes, Eugene, OR, USA) for $15 \mathrm{~min}$ at $37^{\circ} \mathrm{C}$, immediately followed by phase-contrast or fluorescence microscopy using a Leica DMIRB with integrated camera Leica DFC 450C (Leica Microsystems, Wetzlar, Germany). Digital images were identically processed using the advanced LAS version 4.4.0, Build: 454 Leica Microsystems.

mRNA isolation and qPCR. For quantification of RIPK3 mRNA expression in parental melanomas, primary melanocytes, and nevus cells (Figure $2 b$ ), total mRNA was isolated with RNeasy Kit (Qiagen, Hilden, Germany). cDNA was synthesized by SuperScript II Reverse Transcriptase (Invitrogen, Carlsbad, CA, USA). RT qPCR analysis was performed by using KAPA SYBR Fast qPCR (Peqlab, Erlangen, Germany) in the Mx3005P (Stratagene, La Jolla, CA, USA) real-time thermal cycler. Equal cycling conditions were used to amplify genes of interest and reference gene products. HotStarTaq DNA Polymerase was launched by an initial step of $15 \mathrm{~min}$ at $95^{\circ} \mathrm{C}$ followed by 42 cycles of 1 step (denaturation) at $94^{\circ} \mathrm{C}$ for $15 \mathrm{~s}$, 1 step (annealing) at $55^{\circ} \mathrm{C}$ for $30 \mathrm{~s}$, and $1 \mathrm{step}$ (extension) at $72^{\circ} \mathrm{C}$ for $30 \mathrm{~s}$. Melting curve analysis was used to confirm the specific product amplification. RT-PCR efficiency was calculated using standard curve (plotted as a logarithmic function of the CDNA dilution factor) and Mx3005P software (Stratagene). Normalization was performed with primers to $\beta$-actin as described. ${ }^{69}$ The following primer sequences were used for qPCR analysis: RIPK3 forward 5"-CAAGATCGTAAACTCGAAGG -3', RIPK3 reverse $5^{\prime}$-CCGTTCTCCATGAATTTAGT-3'; $\beta$-actin forward $5^{\prime}$-AGAAAATCTGGCACCA CACC-3', $\beta$-actin (ACTB) reverse 5'-GGGGTGTTGAAGGTCTCAAA-3'.

\section{Cytotoxicity assays}

Analysis of living attached cell by crystal violet staining: Cells $\left(1 \times 10^{4}\right)$ were seeded per well in a 96-well plate and cultured for adherence overnight. Cells were stimulated with controls (dimethyl sulfoxide (DMSO) and ethanol), IAP antagonist, zVAD-fmk, Nec-1/Necro-1, NSA, RIPK1 inhibitors (GSK'481 or 7-Cl-ONec-1/Necro-1), RIPK3 inhibitors (GSK'840 or GSK'872), TNFR2-Fc or CD95L alone, or in respective combinations in 96-well plates accordingly described in the respective figure legends. Crystal violet staining of attached, living cells was performed 18-24 h after stimulation in triplicate wells per condition as described elsewhere. ${ }^{70}$ The optical density of control cultures was normalized to $100 \%$ and compared with stimulated cells. In case of combined stimulation of inhibitors together with CD95L or TNF (Supplementary Figure 2D), the spontaneous cytotoxic effect of single diluents and substrates was subtracted from each costimulation to solely show specific DL-induced cell death. For statistical analysis, the S.E.M. was determined for three to four independent experiments of each cell line and stimulatory condition.

Annexin Vexternalization: For detection of phosphatidylserine externalization, cells were stimulated as indicated in the figure legends. Fourteen hours after incubation of cells, trypsinized cells, and the supernatants were collected and resuspended in $1 \times$ Annexin-V binding buffer $(10 \mathrm{mM}$ Hepes, $\mathrm{pH} 7.4,140 \mathrm{mM} \mathrm{NaCl}$, $2,5 \mathrm{mM} \mathrm{CaCl}_{2}$ ) and $2-4 \times 10^{5}$ cells were subsequently stained with Cy5-conjugated Annexin- $V$ exactly according to the manufacturer's instructions (Pharmingen, San Diego, CA, USA), followed by counterstaining (PI; $10 \mu \mathrm{g} / \mathrm{ml}$ ) for $15 \mathrm{~min}$ in the dark at room temperature. For all experiments, $1 \times 10^{4}$ cells were analysed by FACScan (Becton Dickinson \& Co., San Jose, CA, USA) and summarized with FCS Express version 3 programs (De Novo Software, Glendale, CA, USA). Non-stimulated cells served as negative control for Annexin V/PI double stainings.

Analysis of CD95 surface expression. For analysis of CD95 cell surface expression from vector control and RIPK3-overexpressing A375 and IGR cells on stimulation with control (DMSO) and Dabrafenib $(10 \mu \mathrm{M})$ for $2 \mathrm{~h}$ were stained with antiCD95 (Apo-1 lgG1) primary antibody as well as isotype-matched control antibodies followed by FACS analysis as described in detail in Diessenbacher et $\mathrm{al}^{22}$

\section{Conflict of Interest}

The authors declare no conflict of interest.
Acknowledgements. We thank J Murphy, J Silke, and D Vaux for providing MLKL antibodies, $\mathrm{H}$ Walczak for plasmids expressing HF-TRAIL and HF-TNF, and PH Krammer for antibodies to caspase-8, cFLIP, and CD95. Tetralogics Corp. generously provided IAP antagonist compounds. We are indebted to $P$ Meier, A Bosserhoff, and C Gebhardt for helpful discussions. A plasmid coding for CD95L-FC was kindly provided by Pascal Schneider, Epalinges, Switzerland. NSA was a generous gift by Liming Sun and Xiaodong Wang, Beijing, China. Work in the laboratory of ML is funded by EU Horizon 2020 (MelPlex ESR network, Project 5) and grants of the Deutsche Forschungsgemeinschaft (Le 953/6-1, 953/8-1). ML (Project 9 and 10) and PG (Project 10) are supported by Deutsche Forschungsgemeinschaft RTG 2099. Project 9 supports RS and project 10 provides funding for SH. JW is supported by a Heinz-Götze-Memorial Fellowship of Heidelberg University.

1. Cho YS, Challa S, Moquin D, Genga R, Ray TD, Guildford M et al. Phosphorylation-driven assembly of the RIP1-RIP3 complex regulates programmed necrosis and virus-induced inflammation. Cell 2009; 137: 1112-1123.

2. Zhang DW, Shao J, Lin J, Zhang N, Lu BJ, Lin SC et al. RIP3, an energy metabolism regulator that switches TNF-induced cell death from apoptosis to necrosis. Science 2009; 325: 332-336

3. He S, Wang L, Miao L, Wang T, Du F, Zhao L et al. Receptor interacting protein kinase-3 determines cellular necrotic response to TNF-alpha. Cell 2009; 137: 1100-1111.

4. Feoktistova M, Geserick P, Kellert B, Dimitrova DP, Langlais C, Hupe M et al. clAPs block Ripoptosome formation, a RIP1/caspase-8 containing intracellular cell death complex differentially regulated by cFLIP isoforms. Mol Cell 2011; 43: 449-463.

5. Geserick P, Hupe M, Moulin M, Wong WW, Feoktistova M, Kellert B et al. Cellular IAPs inhibit a cryptic CD95-induced cell death by limiting RIP1 kinase recruitment. J Cell Biol 2009: 187: 1037-1054.

6. Vandenabeele P, Galluzzi L, Vanden Berghe T, Kroemer G. Molecular mechanisms of necroptosis: an ordered cellular explosion. Nat Rev Mol Cell Biol 2010; 11: 700-714.

7. Vanden Berghe $T$, Linkermann A, Jouan-Lanhouet $S$, Walczak $H$, Vandenabeele $P$. Regulated necrosis: the expanding network of non-apoptotic cell death pathways. Nat Rev Mol Cell Biol 2014; 15: 135-147.

8. Remijsen Q, Goossens V, Grootjans S, Van den Haute C, Vanlangenakker N, Dondelinger $Y$ et al. Depletion of RIPK3 or MLKL blocks TNF-driven necroptosis and switches towards a delayed RIPK1 kinase-dependent apoptosis. Cell Death Dis 2014; 5: e1004.

9. Tenev T, Bianchi K, Darding M, Broemer M, Langlais C, Wallberg F et al. The Ripoptosome, a signaling platform that assembles in response to genotoxic stress and loss of IAPs. Mol Cell 2011; 43: 432-448.

10. Murphy JM, Silke J. Ars Moriendi; the art of dying well - new insights into the molecular pathways of necroptotic cell death. EMBO Rep 2014; 15: 155-164.

11. Sun L, Wang H, Wang Z, He S, Chen S, Liao D et al. Mixed lineage kinase domain-like protein mediates necrosis signaling downstream of RIP3 kinase. Cell 2012; 148: 213-227.

12. Cai Z, Jitkaew S, Zhao J, Chiang HC, Choksi S, Liu J et al. Plasma membrane translocation of trimerized MLKL protein is required for TNF-induced necroptosis. Nat Cell Biol 2014; 16: $55-65$.

13. Kaczmarek A, Vandenabeele P, Krysko DV. Necroptosis: the release of damage-associated molecular patterns and its physiological relevance. Immunity 2013; 38: 209-223.

14. Hildebrand JM, Tanzer MC, Lucet IS, Young SN, Spall SK, Sharma P et al. Activation of the pseudokinase MLKL unleashes the four-helix bundle domain to induce membrane localization and necroptotic cell death. Proc Natl Acad Sci USA 2014; 111: 15072-15077.

15. Schilling $R$, Geserick $P$, Leverkus $M$. Characterization of the ripoptosome and its components: implications for anti-inflammatory and cancer therapy. Methods Enzymol 2014; 545: 83-102.

16. Jouan-Lanhouet S, Arshad MI, Piquet-Pellorce C, Martin-Chouly C, Le Moigne-Muller G, Van HF et al. TRAIL induces necroptosis involving RIPK1/RIPK3-dependent PARP-1 activation. Cell Death Differ 2012; 19: 2003-2014.

17. Vince JE, Chau D, Callus B, Wong WW, Hawkins CJ, Schneider $P$ et al. TWEAK-FN14 signaling induces lysosomal degradation of a clAP1-TRAF2 complex to sensitize tumor cells to TNFalpha. J Cell Biol 2008; 182: 171-184.

18. Obexer $\mathrm{P}$, Ausserlechner MJ. X-linked inhibitor of apoptosis protein-a critical death resistance regulator and therapeutic target for personalized cancer therapy. Front Oncol 2014; 4: 197.

19. Spagnolo F, Ghiorzo P, Queirolo P. Overcoming resistance to BRAF inhibition in BRAF-mutated metastatic melanoma. Oncotarget 2014; 5: 10206-10221.

20. Flaherty KT, Infante JR, Daud A, Gonzalez R, Kefford RF, Sosman J et al. Combined BRAF and MEK inhibition in melanoma with BRAF V600 mutations. N Engl J Med 2012; 367: 1694-1703.

21. Hanahan D, Weinberg RA. Hallmarks of cancer: the next generation. Cell 2011; 144: 646-674 22. Diessenbacher P, Hupe M, Sprick MR, Kerstan A, Geserick P, Haas TL et al. NF-kappaB inhibition reveals differential mechanisms of TNF versus TRAIL-induced apoptosis upstream or at the level of caspase-8 activation independent of clAP2. J Invest Dermatol 2008; 128: 1134-1147.

23. Vince JE, Pantaki D, Feltham R, Mace PD, Cordier SM, Schmukle AC et al. TRAF2 must bind to cellular inhibitors of apoptosis for tumor necrosis factor (tnf) to efficiently activate nf-\{kappa\}b and to prevent tnf-induced apoptosis. J Biol Chem 2009; 284: 35906-35915. 
24. Mandal P, Berger SB, Pillay S, Moriwaki K, Huang C, Guo H et al. RIP3 induces apoptosis independent of pronecrotic kinase activity. Mol Cell 2014; 56: 481-495.

25. Cook WD, Moujalled DM, Ralph TJ, Lock P, Young SN, Murphy JM et al. R. Cell Death Differ 2014; 21: 1600-1612.

26. Varfolomeev E, Blankenship JW, Wayson SM, Fedorova AV, Kayagaki N, Garg P et al. IAP antagonists induce autoubiquitination of C-IAPs, NF-kappaB activation, and TNFalpha-dependent apoptosis. Cell 2007; 131: 669-681.

27. Vince JE, Wong WW, Khan N, Feltham R, Chau D, Ahmed AU et al. IAP antagonists target CIAP1 to induce TNFalpha-dependent apoptosis. Cell 2007; 131: 682-693.

28. Bertrand MJ, Milutinovic S, Dickson KM, Ho WC, Boudreault A, Durkin J et al. clAP1 and cIAP2 facilitate cancer cell survival by functioning as E3 ligases that promote RIP1 ubiquitination. Mol Cell 2008; 30: 689-700.

29. Gaither A, Porter D, Yao Y, Borawski J, Yang G, Donovan J et al. A Smac mimetic rescue screen reveals roles for inhibitor of apoptosis proteins in tumor necrosis factor-alpha signaling. Cancer Res 2007; 67: 11493-11498.

30. Moujalled DM, Cook WD, Okamoto T, Murphy J, Lawlor KE, Vince JE et al. TNF can activate RIPK3 and cause programmed necrosis in the absence of RIPK1. Cell Death Dis 2013; 4 : e465

31. Degterev A, Huang Z, Boyce M, Li Y, Jagtap P, Mizushima N et al. Chemical inhibitor of nonapoptotic cell death with therapeutic potential for ischemic brain injury. Nat Chem Biol 2005; 1: 112-119.

32. Kaiser WJ, Sridharan H, Huang C, Mandal P, Upton JW, Gough PJ et al. Toll-like receptor 3mediated necrosis via TRIF, RIP3, and MLKL. J Biol Chem 2013; 288: 31268-31279.

33. Harris PA, Bandyopadhyay D, Berger SB, Campobasso N, Capriotti CA, Cox JA et al. Discovery of small molecule RIP1 kinase inhibitors for the treatment of pathologies associated with necroptosis. ACS Med Chem Lett 2013; 4: 1238-1243.

34. Ofengeim D, Yuan J. Regulation of RIP1 kinase signalling at the crossroads of inflammation and cell death. Nat Rev Mol Cell Biol 2013; 14: 727-736.

35. Spagnolo F, Queirolo P. Upcoming strategies for the treatment of metastatic melanoma. Arch Dermatol Res 2012; 304: 177-184.

36. Flaherty KT, Puzanov I, Kim KB, Ribas A, McArthur GA, Sosman JA et al. Inhibition of mutated, activated BRAF in metastatic melanoma. N Engl J Med 2010; 363: 809-819.

37. Li JX, Feng JM, Wang Y, Li XH, Chen XX, Su Y et al. The B-Raf(V600E) inhibitor dabrafenib selectively inhibits RIP3 and alleviates acetaminophen-induced liver injury. Cell Death Dis 2014; 5: e1278.

38. Karl I, Jossberger-Werner M, Schmidt N, Horn S, Goebeler M, Leverkus M et al. TRAF2 inhibits TRAlL- and CD95L-induced apoptosis and necroptosis. Cell Death Dis 2014; 5: e1444.

39. Lidsky M, Antoun G, Speicher P, Adams B, Turley R, Augustine C et al. Mitogen-activated protein kinase (MAPK) hyperactivation and enhanced NRAS expression drive acquired vemurafenib resistance in V600E BRAF melanoma cells. J Biol Chem 2014; 289: 27714-27726.

40. Geserick P, Herlyn M, Leverkus M. On the TRAIL to overcome BRAF-inhibitor resistance. $J$ Invest Dermatol 2014; 134: 315-318.

41. Wan $Y$, Liu T, Hou X, Dun Y, Guan P, Fang H. Antagonists of IAP Proteins: Novel Antitumor Agents. Curr Med Chem 2014; 21: 3877-3892.

42. Sun H, Lu J, Liu L, Yang CY, Wang S. Potent and selective small-molecule inhibitors of CIAP1/2 proteins reveal that the binding of Smac mimetics to XIAP BIR3 is not required for their effective induction of cell death in tumor cells. ACS Chem Biol 2014; 9: 994-1002.

43. Vogler M, Walczak H, Stadel D, Haas TL, Genze F, Jovanovic M et al. Targeting XIAP bypasses Bcl-2-mediated resistance to TRAIL and cooperates with TRAIL to suppress pancreatic cancer growth in vitro and in vivo. Cancer Res 2008; 68: 7956-7965.

44. Seigal BA, Connors WH, Fraley A, Borzilleri RM, Carter PH, Emanuel SL et al. The discovery of macrocyclic XIAP antagonists from a DNA-programmed chemistry library, and their optimization to give lead compounds with in vivo antitumor activity. J Med Chem 2015; 58 : 2855-2861.

45. Newton K, Dugger DL, Wickliffe KE, Kapoor N, de Almagro MC, Vucic D et al. Activity of protein kinase RIPK3 determines whether cells die by necroptosis or apoptosis. Science 2014; 343: 1357-1360.

46. Murphy JM, Czabotar PE, Hildebrand JM, Lucet IS, Zhang JG, Alvarez-Diaz S et al. The pseudokinase MLKL mediates necroptosis via a molecular switch mechanism. Immunity 2013; 39: 443-453.

47. Wu J, Huang Z, Ren J, Zhang Z, He P, Li Y et al. Mlkl knockout mice demonstrate the indispensable role of Mlkl in necroptosis. Cell Res 2013; 23: 994-1006.

48. Dondelinger Y, Declercq W, Montessuit S, Roelandt R, Goncalves A, Bruggeman I et al. MLKL compromises plasma membrane integrity by binding to phosphatidylinositol phosphates. Cell Rep 2014; 7: 971-981.

49. Fukasawa M, Kimura M, Morita S, Matsubara K, Yamanaka S, Endo C et al. Microarray analysis of promoter methylation in lung cancers. J Hum Genet 2006; 51: 368-374.

50. Moriwaki K, Bertin J, Gough PJ, Orlowski GM, Chan FK. Differential roles of RIPK1 and RIPK3 in TNF-induced necroptosis and chemotherapeutic agent-induced cell death. Cell Death Dis 2015; 6: e1636.
51. Jonsson G, Busch C, Knappskog S, Geisler J, Miletic H, Ringner M et al. Gene expression profiling-based identification of molecular subtypes in stage IV melanomas with different clinical outcome. Clin Cancer Res 2010; 16: 3356-3367.

52. Baylin SB, Jones PA. A decade of exploring the cancer epigenome - biological and translational implications. Nat Rev Cancer 2011; 11: 726-734.

53. Rickard JA, O'Donnell JA, Evans JM, Lalaoui N, Poh AR, Rogers T et al. RIPK1 regulates RIPK3-MLKL-driven systemic inflammation and emergency hematopoiesis. Cell 2014; 157: $1175-1188$.

54. Kaiser WJ, Upton JW, Long AB, Livingston-Rosanoff D, Daley-Bauer LP, Hakem R et al. RIP3 mediates the embryonic lethality of caspase-8-deficient mice. Nature 2011; 471: 368-372.

55. Oberst A, Dillon CP, Weinlich R, McCormick LL, Fitzgerald P, Pop C et al. Catalytic activity of the caspase-8-FLIP(L) complex inhibits RIPK3-dependent necrosis. Nature 2011; 471: 363-367.

56. Zhang H, Zhou X, McQuade T, Li J, Chan FK, Zhang J. Functional complementation between FADD and RIP1 in embryos and lymphocytes. Nature 2011; 471: 373-376.

57. Upton JW, Kaiser WJ, Mocarski ES. DAI/ZBP1/DLM-1 complexes with RIP3 to mediate virus-induced programmed necrosis that is targeted by murine cytomegalovirus vIRA. Cell Host Microbe 2012; 11: 290-297.

58. He S, Liang $Y$, Shao $F$, Wang $X$. Toll-like receptors activate programmed necrosis in macrophages through a receptor-interacting kinase-3-mediated pathway. Proc Natl Acad Sci USA 2011; 108: 20054-20059.

59. Kaiser WJ, Daley-Bauer LP, Thapa RJ, Mandal P, Berger SB, Huang C et al. RIP1 suppresses innate immune necrotic as well as apoptotic cell death during mammalian parturition. Proc Natl Acad Sci USA 2014; 111: 7753-7758.

60. Dillon CP, Weinlich R, Rodriguez DA, Cripps JG, Quarato G, Gurung $P$ et al. RIPK1 blocks early postnatal lethality mediated by caspase-8 and RIPK3. Cell 2014; 157 1189-1202.

61. Jang TH, Zheng C, Li J, Richards C, Hsiao YS, Walz T et al. Structural study of the RIPoptosome core reveals a helical assembly for kinase recruitment. Biochemistry 2014; 53 5424-5431.

62. Takahashi N, Vereecke L, Bertrand MJ, Duprez L, Berger SB, Divert T et al. RIPK1 ensures intestinal homeostasis by protecting the epithelium against apoptosis. Nature $2014 ; \mathbf{5 1 3}$ 95-99.

63. Silke J, Kratina T, Chu D, Ekert PG, Day CL, Pakusch M et al. Determination of cell survival by RING-mediated regulation of inhibitor of apoptosis (IAP) protein abundance. Proc Natl Acad Sci USA 2005; 102: 16182-16187.

64. Byers HR, Etoh T, Doherty JR, Sober AJ, Mihm Jr MC. Cell migration and actin organization in cultured human primary, recurrent cutaneous and metastatic melanoma. Time-lapse and image analysis. Am J Pathol 1991; 139: 423-435.

65. Griesser J, Kaufmann D, Eisenbarth I, Bauerle C, Krone W. Ras-GTP regulation is not altered in cultured melanocytes with reduced levels of neurofibromin derived from patients with neurofibromatosis 1 (NF1). Biol Chem Hoppe Seyler 1995; 376: 91-101.

66. Boukamp P, Petrussevska RT, Breitkreutz D, Hornung J, Markham A, Fusenig NE. Normal keratinization in a spontaneously immortalized aneuploid human keratinocyte cell line. J Cell Biol 1988; 106: 761-771.

67. Bossen C, Ingold K, Tardivel A, Bodmer JL, Gaide O, Hertig S et al. Interactions of tumor necrosis factor (TNF) and TNF receptor family members in the mouse and human. $J$ Biol Chem 2006; 281: 13964-13971.

68. Geserick P, Drewniok C, Hupe M, Haas TL, Diessenbacher P, Sprick MR et al. Suppression of cFLIP is sufficient to sensitize human melanoma cells to TRAIL- and CD95L-mediated apoptosis. Oncogene 2008; 27: 3211-3220.

69. Kavuri SM, Geserick P, Berg D, Dimitrova DP, Feoktistova M, Siegmund D et al. Cellular FLICE-inhibitory protein (CFLIP) isoforms block CD95- and TRAIL death receptor-induced gene induction irrespective of processing of caspase-8 or cFLIP in the death-inducing signaling complex. J Biol Chem 2011; 286: 16631-16646.

70. Makarov R, Geserick P, Feoktistova M, Leverkus M. Cell death in the skin: how to study its quality and quantity? Methods Mol Biol 2013; 961: 201-218.

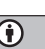

Cell Death and Disease is an open-access journal published by Nature Publishing Group. This work is licensed under a Creative Commons Attribution 4.0 International License. The images or other third party material in this article are included in the article's Creative Commons license, unless indicated otherwise in the credit line; if the material is not included under the Creative Commons license, users will need to obtain permission from the license holder to reproduce the material. To view a copy of this license, visit http://creativecommons. org/licenses/by/4.0/ 